\title{
HSCs Contribute Actively to Native Multilineage Hematopoiesis but With Reduced Differentiation Capacity Upon Aging
}

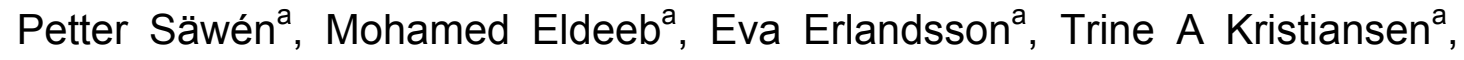
Cecilia Laterza $^{\mathrm{d}, \mathrm{e}}$, Zaal Kokaia ${ }^{\mathrm{d}, \mathrm{e}}$, Göran Karlsson ${ }^{\mathrm{a}, \mathrm{d}, \mathrm{e}}$, Joan Yuan ${ }^{\mathrm{a}, \mathrm{d}, \mathrm{e}}$, Shamit Soneji $^{\mathrm{a}, \mathrm{d}, \mathrm{e}}$, Pankaj K. Mandal ${ }^{\mathrm{b}, \mathrm{c}}$, Derrick J Rossi ${ }^{\mathrm{b}, \mathrm{c}}$ and David Bryder ${ }^{\mathrm{a}, \mathrm{d}, \mathrm{e}, \mathrm{f}}$

a Lund University, Medical Faculty, Department of Laboratory Medicine, Division of Molecular Hematology, Klinikgatan 26, BMC B12, 221 84, Lund, Sweden

${ }^{\mathrm{b}}$ Department of Stem Cell and Regenerative Biology, Harvard University, Cambridge, MA 02138, USA

${ }^{c}$ Program in Cellular and Molecular Medicine, Division of Hematology/Oncology, Boston Children's Hospital, MA 02116, USA

d StemTherapy, Lund University

${ }^{\mathrm{e}}$ Lund Stem Cell Center, Lund University

${ }^{f}$ Sahlgrenska Cancer Center, Gothenburg University

Classification: Biological Sciences; Cell Biology

Short title: Native HSC-derived Hematopoiesis Declines With Age

Corresponding author: David Bryder

Adress: Lund University, Medical Faculty, Department of Laboratory Medicine, Division of Molecular Hematology, Klinikgatan 26, BMC B12, 221 84, Lund, Sweden

E-mail: David.Bryder@med.lu.se

Phone number: $\quad+46-46-2223951$

Keywords: Hematopoietic Stem Cell, Native Hematopoiesis, Aging 


\section{ABSTRACT}

A hallmark of adult hematopoiesis is the continuous replacement of blood cells with limited lifespans. It is well established that adult hematopoietic stem cells (HSCs) are active contributors to these processes after transplantation, yet their role in native hematopoiesis has recently been called into question. Here, we use inducible lineage tracing from genetically marked adult HSCs to explore their roles in the steady state. We show that adult HSCs contribute robustly to all lineages via intermediate progenitor cells, but with neglible production of hematopoietic cells with a known fetal origin. We further reveal that the timing for regeneration of distinct blood lineages varies substantially. Finally, HSC contribution to multilineage hematopoiesis in aged animals declines with increasing age. Therefore, while HSCs are active contributors to native adult hematopoiesis, it appears that the numerical increase of HSCs is a physiologically relevant compensatory mechanism to account for a reduced differentiation capacity with age. 


\section{INTRODUCTION}

HSC-derived hematopoiesis has usually been studied in the setting of transplantation (Benz et al., 2012; Biasco et al., 2016; Dykstra et al., 2007; Lu, Neff, Quake, \& Weissman, 2011; Nilsson, Pronk, \& Bryder, 2015; Wu et al., 2014), an experimental paradigm that has been the foundation of hematopoietic research for decades (Siminovitch, McCulloch, \& Till, 1963; Till \& McCulloch 1961) and which has established hallmark properties of HSCs such as multi-potency and self-renewal. However, while the transplantation assay has provided key insights, not the least with relevance for the clinical use in bone marrow (BM) transplantation, it might not reflect the contribution of HSCs to ongoing and unperturbed steady state hematopoiesis accurately. This is because transplantation is conducted under highly non-physiological conditions wherein HSCs are forced to proliferate to rebuild an entire hematopoietic hierarchy in a myeloablated bone marrow micro-environment. Therefore, there is a need to approach HSC biology also in more unperturbed settings.

While the overall structure of hematopoiesis is rather well established (Bryder, Rossi, \& Weissman, 2006), the degree by which HSCs contribute to adult hematopoiesis in the steady state is more unclear. This includes whether the proposed differentiation routes for the hematopoietic lineages are obligatory, or whether alternative/complementary pathways exist. Furthermore, cells of the different hematopoietic lineages have not only distinct homeostatic functions and maintenance mechanisms (Bando \& Colonna, 2016; Dzierzak \& Philipsen, 2013; Rodvien \& Mielke, 1976) but also 
display dramatically different lifespans (Galli, Borregaard, \& Wynn, 2011; Harker et al., 2000; Van Putten, 1958; Westera et al., 2013). As a consequence, the rates by which separate adult-derived blood cell lineages must be replenished differ substantially. At the extreme end, certain hematopoietic cell types generated during the fetal period appear completely devoid of replenishment from adult progenitors, and rather rely on homeostatic proliferation for their maintenance (Ginhoux \& Guilliams, 2016; Kantor, Stall, Adams, Watanabe, \& Herzenberg, 1995).

Recent developments of transgenic mouse models that allow for identification (Acar et al., 2015; J. Y. Chen et al., 2016; Gazit et al., 2014) and evaluation of HSCs biology have facilitated studies of native in vivo hematopoiesis (Busch et al., 2015; Sawai et al., 2016; Sun et al., 2014; Wilson et al., 2008). Using one such model, we recently revealed that most adult HSCs are highly quiescent, which is strikingly different in the transplantation scenario (Säwén et al., 2016). Other models have been used for lineage tracing from HSCs (Busch et al., 2015; Sawai et al., 2016; Sun et al., 2014). In one of these, lineage tracing was conducted via random genetic integration of an inducible transposable genetic element, leading to the proposition that native hematopoiesis involves a large number of actively contributing progenitor cell clones, which are only rarely shared among hematopoietic lineages (Sun et al., 2014). More common approaches for lineage tracing involve the use of cell type specific recombinases, that function to irreversibly mark a cell of interest and with time its descendants. While elegant and extensively used among developmental biologists, such 
approaches have only sparsely been applied to adult HSCs, and with seemingly contradictory results. Using a Tie2-driven model, Busch et al. concluded a substantial hematopoietic contribution/maintenance from progenitors rather than HSCs (Busch et al., 2015), which at least to some extent would appear compatible with the results from Sun et al. (Sun et al., 2014). By contrast, Sawai et al. utilized a Pdzk1ip1-based CreERT2 system and suggested robust HSC labeling and hematopoiesis from adult HSCs (Sawai et al., 2016).

To try to assess these potential ambiguities, we here investigated the degree to which HSCs contribute to steady state adult hematopoiesis by using an inducible Fgd5-based HSC lineage tracing model (Gazit et al., 2014). We observed dramatic differences with regards to HSC contribution to adaptive immunity (slow) and the myeloerythroid lineages (fast), with HSCs contributing to the platelet lineage with the most rapid kinetics. The regeneration of terminal cell fates was closely mirrored at the level of each intermediate myeloerythroid precursor. These findings are consistent with adult HSCs as highly active contributors to multilineage hematopoiesis not only following transplantation, but also during the steady state. However, when approached in the situation of chronological aging, we noted diminished mature blood cell output from aged HSCs that could be traced to the first differentiation events from HSCs. These results suggest that the previously proposed fetal to adult switch (Bowie et al., 2007), in which HSCs alter their properties from more excessive proliferation/differatiation to a more dormant state in the adult, extends gradually throughout adulthood. As a consequence, the well-known 
numerical increase of HSCs with age (Morrison, Wandycz, Akashi, Globerson,

\& Weissman, 1996; Rossi et al., 2005; Sudo, Ema, Morita, \& Nakauchi, 2000)

appears to represent a physiologically relevant mechanism to account for reduced HSC differentiation with age. 


\section{RESULTS}

\section{Fgd5-CreERT2-based lineage tracing allows for assessment of HSC contributions to unperturbed hematopoiesis}

Using a transcriptome based screen of more than 40 different hematopoietic cell types, Fgd5 (FYVE, RhoGEF and PH domain containing 5) was identified as a HSC-expressed gene that is rapidly downregulated upon differentiation. That Fgd5 expression marks all HSCs was confirmed through functional studies using an Fgd5 knock-in reporter strain (Gazit et al., 2014). To further detail the HSC specificity of Fgd5, we first acquired transcriptome data from 11,581 individual lineage-marker negative, c-kit positive and CD45 positive bone marrow cells $\left(\right.$ Lin $\left.^{-} \mathrm{kit}^{+}\right)$. The Lin`kit $^{+}$population contains a range of different immature hematopoietic progenitor cells (Pronk et al., 2007). Therefore, Lin`kit ${ }^{+}$cells provided a benchmark to which other more defined/specific hematopoietic progenitor subsets could be compared. Next, we took advantage of an Fgd5 reporter strain in which a ZsGreen-2ACreERT2 allele was knocked into the endogenous Fgd5 locus (hereafter Fgd5 ${ }^{\text {CreERT2/+ }}$ mice) (Fig. 1B) (Gazit et al., 2014). We sorted either Lin ${ }^{-}$ kit $^{+}$Fgd5 $5^{+}$cells (Fig. 1A middle; 793 cells, Fgd5 ${ }^{+}$), or Fgd5 $^{+}$cells with a stringent Lin ${ }^{-k i t}{ }^{+}$Sca $-1^{+}$CD48-CD150+ HSC phenotype (Fig. 1A right, 519 cells, HSC-Fgd5 ${ }^{+}$. All Fgd5 ${ }^{+}$and HSC-Fgd5 ${ }^{+}$data were aggregated with the Lin ${ }^{-k i t}{ }^{+}$ transcriptome data, which was followed by identification of the most significant gene vectors using principal component analysis (PCA). Data was then visualized using t-distributed stochastic neighbor embedding (tSNE) 
dimensionality reduction (Fig. 1A). Lin $^{-1}{ }^{+}{ }^{+}$cells were extensively scattered across the two dimensions (Fig. 1A, left), in agreement with the heterogeneity of these cells. By contrast, $\mathrm{Fgd}^{+}$cells, regardless if sorted based on additional HSC markers, formed a distinct and highly overlapping cluster (Fig. $1 \mathrm{~A}$, middle and right). This cluster localized to a region with very few cells when evaluating Lin $^{-k_{i t}}{ }^{+}$cells (Fig. 1A, left, dotted area), emphasizing the HSC-specificity of the Fgd5 reporter and the low HSC frequency within the larger Linkit ${ }^{+}$fraction.

We next generated a lineage tracing model by crossing Fgd5 ${ }^{\text {CreERT2/+ }}$ mice to Rosa26 ${ }^{\text {Tomato/+ }}$ mice (Fig. 1B). In this model, HSCs can be identified based on ZsGreen expression, while Tamoxifen administration leads to irreversible and heritable Tomato labeling of HSCs and, over time, their offspring (Fig. 1C). To confirm the model, we evaluated Tomato label in HSC and BM progenitor cells 48 hours after a single injection (1x) of Tamoxifen. This revealed labeling of a fraction of candidate HSCs, with virtually no labeling in other $\mathrm{c}-\mathrm{kit}^{+}$progenitor fractions (Fig. 1D and Fig. S1). This established HSC specific labeling and a relatively low differentiation rate of HSCs in steady state (Säwén et al., 2016; Wilson et al., 2008). To illustrate our ability to detect Tomato label in peripheral blood (PB) cells, we assessed Tomato expression in defined cell types from mice that had received Tamoxifen 8-48 weeks previously (Fig. 1D, lower right). Complementary to immunophenotypic identification of initially labeled BM cells as HSCs (Fig. 1D and data not shown), we evaluated the proliferation history of Tomato labeled HSPCs 5 days after a pulse of Tomato labeling by evaluation of transgenic 
H2B-mCherry label retention (Fig. 1E) (Säwén et al., 2016). Among HSCs, this revealed a strong correlation between a restricted proliferative history and Tomato labeling.

Finally, to corroborate that Tomato labeled phenotypic HSCs are bona fide HSCs, we injected mice with Tamoxifen and isolated candidate Tomato positive and negative HSCs 48 hours later. Sorted cells were transplanted at limiting dilution (5 cells/mouse). This revealed long-term multilineage reconstitution in 5/8 recipients transplanted with Tomato ${ }^{+} \mathrm{HSCs}$ (Fig. 1F).

\section{Fgd5-lineage tracing reveals that HSCs generate different types of hematopoietic progeny with distinct kinetics}

Encouraged by the highly specific HSC label observed after Tamoxifen administration to Fgd5 ${ }^{\mathrm{CreERT} 2 /+}$ Rosa26 ${ }^{\text {Tomato/+ }}$ mice (Fig. 1), we next set out to perform label tracing studies of hematopoietic generation from HSCs. For this, we labeled cohorts of Fgd5 ${ }^{\mathrm{CreERT} 2 /+}$ Rosa26 ${ }^{\text {Tomato/+ }}$ mice with one injection of Tamoxifen and chased groups of mice for different periods of time up to 83 weeks after labeling. At end point analyses, the fraction of Tomato+ cells was determined in various hematopoietic compartments to assess the HSC contribution to progenitor pools and mature blood cell subsets (Fig. S1). The frequencies of Tomato+ cells for each investigated subset were next related to the fraction of Tomato labeled HSC (Fig. 2A, mean 13\%+/- 9\%) in individual mice (Fig. 2B, and Fig. S2). The fraction of labeled HSCs was generally higher in mice analyzed beyond 4 days of chase compared to mice analyzed 
after shorter chase periods. However, no further increase in HSC labeling was noted after longer periods of chase (Fig. 2A).

First, we investigated Tomato label progression into the immature lineage negative, Sca-1 positive and c-kit positive (LSK) compartment, fractionated further using the Slam markers CD48 and CD150 (Kiel, Yilmaz, Iwashita, Terhorst, \& Morrison, 2005) (Fig. 2C and Fig. S1A). We used this approach to identify HSCs (LSKCD150 CD48 $)$ and different multipotent progenitor fractions (MPPs: LSKCD150CD48-, MPP²: LSKCD150+CD48 ${ }^{+}$, $\mathrm{MPP}^{3 / 4}:$ LSKCD150-CD48 $^{+}$.

LSKCD150'CD48 $^{-}$MPPs are immature multipotent progenitors distinguished from HSCs by their limited self-renewal potential (Kiel et al., 2005; Kiel, Yilmaz, \& Morrison, 2008; Ugale et al., 2014). Of the evaluated progenitor subsets in our work, this subset was generated from HSCs with the fastest kinetics, with near equilibrium to HSC label reached already by 4 weeks (Fig. 2B).

MPP $^{2}$ cells represent a rare subset of cells with more undefined lineage/developmental affiliations. This prompted us to first elucidate their developmental potential. First, we aimed to place these cells within a transcriptional framework established by other, more established, hematopoietic progenitors. For this, we obtained gene expression data from a panel of defined stem and progenitor cells using a multiplexed qRT-PCR approach for 48 genes, selected to include cell surface markers, cell cycle regulators and transcription factors associated with hematopoiesis (Table S2). This data, along with that from $\mathrm{MPP}^{2}$ cells, was next visualized using PCA 
(Fig. 2C). This revealed that $\mathrm{MPP}^{2}$ cells clustered closely to Meg/E progenitors (Fig. 2C). Consistent with a close association to the Meg/E lineages, short-term (6 days) culture experiments revealed a more robust generation of both megakaryocyte and erythroid containing colonies from $\mathrm{MPP}^{2} \mathrm{~S}$ compared to other LSK subsets (Fig. S3). When investigating Tomato label progression, MPP ${ }^{2}$ cells reached label equilibrium with HSCs after 32 weeks in $1 \mathrm{x}$ injected mice (Fig. 2B).

$\mathrm{MPP}^{3 / 4}$ cells lack, for the most part, Meg/E lineage potential (Adolfsson et al., 2005; Arinobu et al., 2007; Pietras et al., 2015; Pronk et al., 2007). $\mathrm{MPP}^{3 / 4}$ cells acquired Tomato label with much slower kinetics compared to other LSK fractions (Fig. 2B).

Of the distinct progenitor fractions within the Lin $^{-}$kit $^{+}$fraction (Fig. S1A), megakaryocyte progenitors (MkP) acquired label with the fastest kinetics, reaching label equilibrium with HSCs after 32 weeks. Other myeloerythroid progenitors, including pre-megakaryocytic/erythroid (preMeg/E), pre-colony forming unit-erythroid (pre CFU-E) and pre-granulocyte-macrophage (preGM) progenitors acquired Tomato label with very similar kinetics despite their distinct lineage affiliations, although they never quite reached an equilibrium with HSCs throughout the course of the experiments (Fig. 2B and Fig. S2).

Mature effector cells represent the terminal progeny of HSCs. We observed distinct generation kinetics for different lineages (Fig. 2B). First, we made the general observation that myeloerythroid cells acquired label more rapidly than lymphoid cells. Among the myeloid subsets, platelets acquired Tomato label with the fastest kinetics, followed by granulocytes and 
erythrocytes. Among lymphoid cell types, NK cells displayed faster labeling kinetics followed by B cells. T cells showed the slowest labeling kinetics among lymphoid cells and $\mathrm{CD}^{+} \mathrm{T}$ cells acquired label faster than $\mathrm{CD}^{+} \mathrm{T}$ cells (Fig. 2B). Because the frequency of Tomato $^{+}$cells increased over time in all evaluated lineages, this data demonstrate a continuous contribution of HSCs to all hematopoietic lineages.

While multiple studies have defined populations of hematopoietic progenitors that associate with distinct developmental and/or stages of differentiation (Bryder et al., 2006), it is unknown whether such described progenitors are obligatory intermediates and/or their quantitative association relative to their anticipated mature offspring. Therefore, we interrogated the relationships between the rates of (re)generation of candidate committed myeloerythroid progenitors to those of their proposed mature cell lineage. At the earliest time points evaluated, we observed for all evaluated fractions a higher label in their corresponding progenitors (Fig. 2D). However, this was resolved during the course of the experiments and reached similar equilibrium ratios for all evaluated lineages, although the erythroid lineage displayed somewhat slower kinetics (Fig. 2D). Collectively, these experiments are in line with the view that progenitor generation precedes the generation of mature cells and that previously proposed progenitors appears to be, at least for the most part, obligatory intermediates.

Hematopoiesis after transplantation of HSCs is fundamentally different from unperturbed hematopoiesis (Busch et al., 2015; Sun et al., 2014). However, to what extent the pre-conditioning regimen and co-transplantation 
of mature cells and progenitors influence on hematopoiesis from HSCs is less established. Therefore, we next transplanted wild type recipient mice on continuous Tamoxifen diet with purified Fgd5 ${ }^{\mathrm{CreERT} /{ }^{+}} \mathrm{Rosa} 26^{\text {Tomato/+ }} \mathrm{HSCs}$ or WBM cells. Here, recipient mice were pre-conditioned by either lethal irradiation or antibody mediated CD45-depletion (Palchaudhuri et al., 2016). Due to the HSC specificity of the model, this approach allowed us to monitor the kinetics of the HSC contribution to all lineages after transplantation and compare it to the HSC contribution in steady state (Fig. 2E). Compared to steady state, label progression in transplanted mice were faster (Fig. 2E). When label progression kinetics was compared between HSC and WBM transplanted animals, HSC transplantation resulted in faster label progression, especially into the B cell lineage (Fig. 2E). This likely reflects a significant contribution to the regeneration of the B cell lineage by co-transplanted longlived B-lineage progenitors and mature cells after WBM transplantation. Comparison of label progression after WBM transplantation into irradiated or non-irradiated/antibody-mediated conditioned recipient mice revealed similar label progression kinetics into most mature lineages, with the exception of platelets that displayed a faster label progression in WBM transplanted mice. This suggests that progenitors for platelets are more effectively ablated by irradiation than antibody-mediated pre-conditioning.

Fgd5-mediated HSC lineage tracing corroborates the fetal origin of Langerhans cells, B1a B cells and brain microglial cells 
While a labeling regimen of one Tamoxifen injection allows for accurate kinetic evaluations (Fig. 2A-B, D), this experimental strategy labels only a fraction of HSCs (Fig. 2A) and thus necessitates correlation of label in HSCs to other evaluated cell subsets (Busch et al., 2015) (Fig. 2B). If the original HSC label is low, this might as a consequence not allow for evaluation of the activity of the entire pool of HSCs.

To explore whether we could label the HSC pool more extensively, Fgd5 ${ }^{\text {CreERT2/+ }}$ Rosa26 ${ }^{\text {Tomato/+ }}$ mice were fed Tamoxifen containing food pellets for 16 weeks. To rule out adverse effects of prolonged Tamoxifen treatment on HSC proliferation, these experiments were preceded by a control label retaining experiment using H2B-mCherry mice (Säwén et al., 2016). Following H2B-mCherry induction with Doxycycline, mice were chased for 5 weeks in the presence or absence of Tamoxifen. Prolonged Tamoxifen treatment did not induce any additional proliferation within the HSC compartment, while more differentiated progenitors had readily proliferated in both settings (Fig. 3A).

The 16 weeks labeling period was followed by an extensive (up to 41 weeks) chase period, during which mice received normal chow (Fig. 3B). This labeling strategy resulted in labeling of virtually all candidate HSCs (Fig. 3C). The blood of labeled mice was analyzed regularly to determine the fraction of Tomato $^{+}$cells in PB cell subsets (Fig. S1B). Similar to after 1x Tamoxifen labeling, we observed robust label progression into all PB cell subsets, with similar kinetics in between different lineages (Fig. 3B). However, a more complete HSC labeling resulted in a somewhat faster and more robust label 
progression into all PB cell subsets compared to 1x Tamoxifen labeling (Fig. 2E). This was most evident for the lymphoid lineages, where the majority of PB cells had been generated from HSCs at the experiment end point upon prolonged Tamoxifen administration, whereas the ratio of labeled lymphocytes vs. labeled HSCs was low $(>0,5)$ even after 83 weeks of chase in $1 x$ Tamoxifen labeled mice (Fig. 2 B and E, 3B).

From endpoint mice in which the pool of HSCs was almost completely labeled (Fig. 3C), we next interrogated the skin epidermis for Tomato ${ }^{+}$ contribution to granulocytes and Langerhans cells. Granulocytes were almost completely Tomato positive, while Langerhans cells were devoid of label (Fig. 3D, lower left), in line with the fetal origin and self-maintenance of the latter cells (Collin \& Milne, 2016). Next, we interrogated Tomato expression in $\mathrm{V} \gamma 3 \delta^{+}$ T cells, an established fetal derived T cell subset (Havran \& Allison, 1990). To our surprise, this revealed robust Tomato labeling of $\mathrm{V} \gamma 3 \delta^{+} \mathrm{T}$ cells (Fig. 3D, lower left). However, closer examination revealed high expression of ZsGreen in these cells (Fig. 3B, lower middle). Therefore, rather than establishing adult contribution to this lineage, these experiments established Fgd5-CreERT2 transgene expression in $\mathrm{V} \gamma 3 \delta^{+} \mathrm{T}$ cells.

B1a B cells represent an invariant subtype of B cells with a fetal origin that is primarily located in the peritoneum (Hayakawa, Hardy, \& Herzenberg, 1985), where they co-exists with more traditional B1b and B2 B cells in adult mice. While less than $10 \%$ of B1a B cells displayed Tomato label, around $50 \%$ of $B 1 b$ B cells and the vast majority of $B 2 B$ cells (Fig. 3D right) were Tomato $^{+}$(comparable to levels in PB). This is in line with a more strict fetal 
origin of B1a B cells, the ontogenically mixed origin of B1b B cells (Kantor et al., 1995) and an adult HSC origin of most B2 B cells.

Finally, we investigated adult HSC contribution to microglial cells of the brain, a subset of central nervous system myeloid cells that has been proposed to arise entirely from embryonic precursor cells (Alliot, Godin, \& Pessac, 1999). Evaluations by confocal microscopy of the brain parenchyma revealed no detectable Tomato expression in IBA-1 ${ }^{+}$microglia (Fig. 3E), while Fgd5 expressing endothelial cells (Cheng et al., 2012; Gazit et al., 2014) displayed abundant Tomato expression (Fig. 3E middle). These results confirm the strict fetal origin of microglia in steady state.

\section{Native hematopoiesis from HSCs declines with aging}

We next set out to investigate how chronological aging influence on HSC contribution to hematopoiesis. To achieve rapid and robust labeling of HSCs, we labeled juvenile and aged $\mathrm{Fgd} 5^{\mathrm{CreERT2/+}} \mathrm{Rosa} 26^{\text {Tomato/+ }}$ mice by injecting Tamoxifen for five consecutive days (5x). Labeling was followed by evaluation of the fraction of Tomato+ cells in HSC and MPP fractions of the BM LSK compartment one day after the last Tamoxifen injection.

In aged mice, the initial labeling was highly specific to HSCs, with only low levels of labeling in $\mathrm{MPP}^{2}$ cells. In sharp contrast, a larger fraction of LSKCD150`CD48 MPPs were labeled in juvenile mice (Fig. 4A). Next we correlated how increasing age influences on the HSC generation of other LSK/MPP subsets. Fgd5 ${ }^{\text {CreERT2/+}}{ }^{\text {Rosa } 26^{\text {Tomato/+ }}}$ mice between 6 and 96 weeks of age were labeled using a 5x Tamoxifen injection scheme, before evaluation 
of Tomato label in HSCs/MPP $2-4$ days later. Ratios of the fraction of labeled MPPs vs. labeled HSCs in corresponding mice was calculated and plotted against mouse age at labeling (Fig. 4B). This established that label progression into all MPP subsets in aged mice was substantially lower when compared to young adult mice and further revealed that the HSC contribution to MPPs and $\mathrm{MPP}^{3 / 4} \mathrm{~S}$ gradually declines with age towards very little replenishment of in particular $\mathrm{MPP}^{3 / 4}$ in very old age (Fig. 4B).

To evaluate the functional potential of initially Tomato-labeled MPPs, we FACS sorted HSCs and different MPP subsets isolated from non-labeled Fgd5 ${ }^{\text {CreERT2/+}}{ }^{\text {Rosa2 }} 6^{\text {Tomato/+ }}$ mice and transplanted cells into lethally irradiated wild type mice. Recipient mice were provided Tamoxifen containing food pellets throughout the experiment. We analyzed donor chimerism and Tomato labeled PB cells after repetitive PB blood sampling. As expected, we did not observe any multilineage long-term reconstitution or Tomato+ cells in $\mathrm{MPP}^{2} / \mathrm{MPP}^{3 / 4}$ transplanted mice (Fig. 4C). 10 out of $10 \mathrm{HSC}$ transplanted mice were multi lineage reconstituted at 16 weeks post transplantation with high levels of Tomato+ donor cells in all evaluated lineages (Fig. 4C). More surprisingly 2 out of 9 MPP transplanted mice displayed donor reconstitution levels $>1 \%$ in all lineages 16 weeks after transplantation (Fig. 4C). This longterm multilineage reconstitution potential from MPPs was accompanied with robust Tomato labeling among donor cells and revealed that Tomato labeled phenotypic MPPs perform as bona fide HSCs after transplantation (Fig. 4C). By contrast, mice that received MPP cells and displayed only transient myeloid reconstitution never displayed any Tomato+ cells. 
Finally, we were interested in determining whether the age-related decrease in HSC derived MPPs might influence on the generation kinetics of lineage-restricted progenitors and mature blood cells. For this, we labeled juvenile (29 days) and aged (87-89 weeks) Fgd5 ${ }^{\mathrm{CreERT} /+}{ }_{\text {Rosa26 }}^{\text {Tomato/+ }}$ mice with 1x Tamoxifen, which was followed by evaluation of label progression after 18 weeks (Fig. 4D and Fig. S4). While the frequency of Tomato labeled HSCs was similar among the two groups (Fig. S4), all progeny exhibited reduced frequencies of Tomato labeled cells in aged mice, demonstrating a strikingly reduced multilineage differentiation capacity of HSCs as a consequence of age.

\section{DISCUSSION}

In this work, we explored the cellular contribution from HSCs using a HSCspecific lineage tracing approach. Our work revealed robust HSC contribution to adult hematopoiesis, while corroborating the fetal origin of other specific hematopoietic subsets. We observed the fastest label progression into the platelet lineage, which might be related to the recent observations that at least a subset of HSCs appears platelet-biased (Sanjuan-Pla et al., 2013; Shin, Hu, Naramura, \& Park, 2014). Thereafter, erythrocytes and granulocytes acquired label with similar kinetics, although Tomato+ erythrocytes emerged in the peripheral blood somewhat later than granulocytes. This likely reflects the slower turnover of mature erythrocytes compared to other myeloid cells. On the other hand, among granulocytes, we did not find any noticeable differences when evaluating HSC contribution to the neutrophil or eosinophil 
lineages (data not shown), despite the seemingly distinct transcriptional underpinnings of these lineages (Drissen et al., 2016).

Among lymphocytes, the HSC contribution was most rapid and robust to the NK cell lineage. At present, we can say little on whether this reflects an early and distinct progenitor intermediate for NK cells (Wu et al., 2014) or whether NK cells are, at least partially, regenerated through myeloid progenitors (Q. Chen et al., 2015; Grzywacz, Kataria, Blazar, Miller, \& Verneris, 2011). While the extremely slow HSC generation of adaptive immune components (and $\mathrm{T}$ cells in particular) have implications for our understanding of HSCs, by proposing that adult HSCs to a large extent present as myeloid-biased in an unperturbed scenario, our results also suggest the necessity of very harsh conditioning to achieve an "immunological reboot" (the generation of naïve lymphocytes) in certain autoimmune situations (Atkins et al., 2016).

According to current models of hematopoiesis, lineage committed progenitors reside developmentally in between HSCs and their mature progeny, and much work has been aimed at detailing these stages (Adolfsson et al., 2005; Akashi, Traver, Miyamoto, \& Weissman, 2000; Arinobu et al., 2007; Oguro, Ding, \& Morrison, 2013; Pietras et al., 2015; Pronk et al., 2007). What has remained more unknown is the relationships of these defined progenitors not only to HSCs and their mature offspring, but also whether they are obligatory. In our work, we could demonstrate that the generation rates of each evaluated myeloid progenitor subset correlated highly to their corresponding mature offspring, although the generation kinetics varied 
depending on lineage. Thus, although some challenges have recently been raised on how lineage commitment occur from HSCs based on inferences from large-scale single-cell RNA sequencing experiments (Paul et al., 2015; Velten et al., 2017), our data support the more conventional view that the generation of mature myeloid cells is preceded by the generation of obligatory lineage-committed intermediates.

Investigations of immature progenitors revealed that the most rapid label progression associated with LSKCD150'CD48- MPPs. MPPs share many defining properties of HSCs, including multilineage differentiation potential and very low proliferation rates in steady state (Säwén et al., 2016). The distinction of MPPs from HSCs is mainly thought to result from pronounced differences in self-renewal; a property so far entirely evaluated by transplantation. Intriguingly, our work revealed that LSKCD150CD48- MPPs displayed more rapid label kinetics in young mice, which was gradually declining with advancing age. At the same time, we could in agreement with previous studies (Weksberg, Chambers, Boles, \& Goodell, 2008) also demonstrate a minor multilineage HSC activity in this compartment, which correlated exclusively to Fgd5 expression/Tomato labeling. Together with an overall decline in multilineage HSC contribution of aged mice, these results strongly propose a model in which aging associates with reduced/compromised HSC differentiation, which in combination with the wellestablished expansion of HSCs (Morrison et al., 1996; Rossi et al., 2005; Sudo et al., 2000) appears to represent a physiologically relevant 
compensatory mechanisms to sustain multilineage hematopoiesis from HSCs (Fig. 4E).

Compared to MPPs, MPP ${ }^{3 / 4}$ are perhaps easier to approach given their restrictions in lineage potential (lack of Meg/E potential) (Adolfsson et al., 2005; Arinobu et al., 2007; Pietras et al., 2015; Pronk et al., 2007). We found $\mathrm{MPP}^{3 / 4}$ to be regenerated from HSCs with slow kinetics compared to other downstream myeloid progenitor cells, but also to $\mathrm{MPP}^{2}$ cells, that we in agreement with other studies (Pietras et al., 2015) find "primed" towards Meg/E development. Intriguingly, our data proposes a significant self-renewal activity of at least a subset of MPP ${ }^{3 / 4}$, with the demonstration that this fraction never reached label equilibrium with HSCs in any evaluated experimental setting. This might be particularly relevant in the setting of age, a situation in which HSC was found to generate MPP ${ }^{3 / 4}$ very inefficiently (Fig. 4E).

While limited, a few groups have recently approached HSC contribution to native hematopoiesis. Evaluations of hematopoiesis using transposon mobilization led to the conclusion that HSCs are not major contributors to adult hematopoiesis (Sun et al., 2014). To some degree, this conclusion was later corroborated by CreER-mediated labeling of a minor fraction of the adult HSC pool using a Tie2-based CreER driver (Busch et al., 2015). Limited HSC contribution to adult hematopoiesis is in sharp contrast to the results we present here and to results from another recent study (Sawai et al., 2016). Our studies would propose that absence of a HSC specific driver, as in the work from Sun et al., makes interpretations of HSC contribution very complicated, not the least for the lymphoid lineages, while the labeling of only 
a minor fraction of HSCs, as in the work from Busch et al., might select for a subset of HSCs with a rather distinct functional behavior.

In summary, we conclude that although the study of native hematopoiesis highlights fundamental differences with in particular slower regeneration times from HSCs to those seen after transplantation, they regardless corroborate decades of research derived from transplantation experiments, in which HSCs has been proposed to continuously contribute to hematopoiesis. 


\section{MATERIALS AND METHODS}

\section{Mouse procedures}

For inducible marking of HSCs in vivo, we crossed Fgd5-2A-ZsGreenCreERT2 mice (Gazit et al., 2014) (JAX 027789) to Rosa26-LoxP-Stop-LoxPTomato (Madisen et al., 2010) (JAX 007905) mice, resulting in Fgd5 ${ }^{\text {CreERT2/+} R o s a 26 ~}{ }^{\text {Tomato/+ }}$ mice. For simultaneous in vivo tracking of proliferation history and marking of HSCs Fgd5 ${ }^{\text {CreERT2/+ }}$ Rosa26 $6^{\text {Tomato/+ }}$ mice were crossed with Col1a1 ${ }^{\text {tetO/tetO }} \mathrm{ROSA} 26^{\mathrm{H} 2 \mathrm{~B}-\mathrm{mCh} \text { Crry/H2B-mCherry }}$ mice to generate Fgd5 ${ }^{\text {CreERT2/+ }}{ }^{\text {Rosa2 }} 6^{\text {Tomato/+ }}$ Col1a $1^{\text {tetO/+}}$ ROSA26 ${ }^{\text {H2B-mCherry/+ }}$. Such mice were administered doxycycline in food pellets ( $2 \mathrm{~g} / \mathrm{kg}$; Ssniff Spezialdiäten) for 2 weeks followed by 5 weeks of chase before HSC marking by a single i.p. Tamoxifen injection (50 mg/kg) and analysis 5 days later.

Tamoxifen was purchased from Sigma-Aldrich and suspended at 100 $\mathrm{mg} / \mathrm{ml}$ in ethanol and mixed with sunflower oil to a concentration of $10 \mathrm{mg} / \mathrm{ml}$. Tamoxifen was administered by intraperitoneal injections at $50 \mathrm{mg} / \mathrm{kg}$ body weight once $(1 \mathrm{x})$ or for $5(5 \mathrm{x})$ consecutive days. To acquire full/maximal HSC labeling, cohorts of mice were continuously fed Tamoxifen containing food pellets for 16 weeks. Mice on Tamoxifen food were regularly bled (sparsely; 1 2 drops) during the labeling period and during the chase period.

Transplanted recipient mice were subjected to lethal irradiation (950 rad) except CD45.1/2 mice that were CD45-depleted by intravenous injection of an immunotoxin $(3 \mathrm{mg} / \mathrm{kg}$ ) consisting of CD45.2-biotin (clone 104) and streptavidin-Saporin (Advanced Targeting Systems) in a 1:1 molar ratio 3 
days prior to transplantation, as described (Palchaudhuri et al., 2016). All transplanted cells were isolated from CD45.2 Fgd5 ${ }^{\text {CreERT2/+ }}$ Rosa26 ${ }^{\text {Tomato/+ }}$ mice. CD45-depleted recipients were transplanted with $10^{7}$ whole bone marrow (WBM) cells and irradiated mice were transplanted with $3 \times 10^{6}$ WBM cells $(n=7), 200(n=10)$ or $100(n=2)$ HSCs, 635 MPPs $(n=10), 1200 M^{2} P^{2} s$ $(n=5)$ or $7300 \mathrm{MPP}^{3 / 4} \mathrm{~S}(\mathrm{n}=4)$. Tomato ${ }^{+}$and Tomato ${ }^{-}$HSCs were isolated from Fgd5 ${ }^{\text {CreERT2/+}}{ }^{\text {Rosa26 }} 6^{\text {Tomato/+ }}$ mice injected with Tamoxifen 2 days before isolation and transplantation into congenic C57BL/6 $\left(\mathrm{CD} 45.1^{+}\right)$mice on normal chow. Before transplantations of HSCs or MPPs FACS sorted cells were mixed with $3 \times 10^{5}$ WBM competitor cells in $200 \mu$ l PBS supplemented with 2 mM EDTA and 2\% FBS before injection. Where indicated, recipient mice were given Tamoxifen containing food pellets $(400 \mathrm{mg} / \mathrm{kg}$ Tamoxifen Citrate, Ssniff Spezialdiäten) throughout the experiments. At the indicated time point, PB was collected from the tail vein for reconstitution analysis.

H2B-mCherry labeling in Col1a1 ${ }^{\text {tetO/tetO }} \mathrm{ROSA} 26^{\mathrm{H} 2 \mathrm{~B}-\mathrm{mCherry} / \mathrm{H} 2 \mathrm{~B}-\mathrm{mCherry}}$ mice was induced by administration of doxycycline (Säwén et al., 2016). Thereafter, mice were chased for 5 weeks while eating Tamoxifen containing food pellets or normal chow (No TAM), followed by FACS analysis to assess H2BmCherry dilution in HSCs/progenitors.

All mice were maintained at the animal facilities at BMC at Lund University, and were performed with consent from a local ethical committee.

\section{Immunophenotyping and FACS}


Immunophenotyping by FACS was done as described (Säwén et al., 2016) (Table S1). For platelet and erythrocyte analysis, $1 \mu$ of whole blood was taken to $300 \mu \mathrm{I}$ PBS before FACS analysis. Cells were sorted and/or analyzed on a FACS Aria III cell sorter (Becton Dickinson) or on a LSRFortessa (Becton Dickinson).

\section{B1a, Langerhans cells and Vg3+ T cell analysis}

For isolation of peritoneal cells, peritoneal lavage was performed using $10 \mathrm{~mL}$ PBS. For isolation of skin epidermal cells, the flank of the mouse was shaved before excision of skin. The skin was incubated for 25 minutes at $37^{\circ} \mathrm{C}$ in a dissociation buffer (PBS containing $2.4 \mathrm{mg} / \mathrm{ml}$ of dispase (Roche) and $3 \%$ FCS) before separation of dermis from the epidermis. Pieces of epidermis were incubated for 30 minutes at $37^{\circ} \mathrm{C}$ in digestion buffer (PBS supplemented with $1 \mathrm{mg} / \mathrm{ml}$ collagenase IV [Sigma-Aldrich], $100 \mathrm{U} / \mathrm{ml}$ DNase I [Sigma], 2.4 $\mathrm{mg} / \mathrm{ml}$ dispase [Roche] and 3\% FBS) and thereafter filtered and stained against indicated markers. Before analysis, cells were incubated with Propidium lodide (Invitrogen) to exclude dead cells.

\section{Immunohistochemistry}

Mice were deeply anaesthetized with an overdose of pentobarbital and transcardially perfused with cold saline. Brains were post-fixed for 48 hours in $4 \%$ paraformaldehyde (PFA) and incubated in $20 \%$ sucrose for 24 hours before being cut in $30 \mu \mathrm{m}$ thick coronal sections on a microtome. Sections were incubated in blocking solution ( $5 \%$ normal serum and $0.25 \%$ Triton X100 in $0.1 \mathrm{M}$ potassium-phosphate buffered solution) for one hour and 
subsequently overnight at $4^{\circ} \mathrm{C}$ with the primary antibody (Iba1 1:1000 Wako). Fluorophore-conjugated secondary antibody (Molecular Probes or Jackson Laboratories) was diluted in blocking solution and applied for 2 hours at room temperature. Tomato label could be detected without any staining. Nuclei were stained with Hoechst (Molecular Probes) for 10 minutes and sections were mounted with Dabco mounting medium. Images were obtained using confocal microscopy (Zeiss, Germany).

\section{Cell culture}

Single LSKCD $150^{+} \mathrm{CD}_{48}{ }^{+}$cells, MPP ${ }^{3 / 4} \mathrm{~s}$ and HSCs were sorted into Terasaki wells containing $20 \mu \mathrm{l}$ of media (OptiMEM supplemented with $10 \%$ FCS, 1:1000 Gentamicin (Invitrogen), 1:100 GlutaMAX (Invitrogen) and 1:500 $\beta$ mercaptoethanol (Invitrogen) supplemented with cytokines (mSCF (Peprotech) 100ng/ml, TPO (Peprotech) 10ng/ml, IL-3 (Peprotech) 5ng/ml, EPO (Janssen) 5units/ml, human G-CSF (Amgen) 10ng/ml). After 6 days of culture at $37^{\circ} \mathrm{C}$, wells were scored and evaluated for the presence of megakaryocytes and erythroid cells by visual inspection in microscope.

\section{Gene expression analyses}

qRT-PCR analyses using the Fluidigm Biomark HD Platform was done as described (Säwén et al., 2016) (Table S2). PCA on gene expression data from all reference populations was performed using Clustvis, (http://biit.cs.ut.ee/clustvis/). 
Single-cell RNA seq libraries were generated using a Chromium system (10x Genomics) according to the manufacturer's instructions. Two consecutive sequencing runs were performed to achieve enough sequencing depth and data was combined and further analyzed using the Cell Ranger ${ }^{\mathrm{TM}}$ pipeline (10x Genomics). Single-cell RNA sequencing data will be uploaded to GEO upon publication (accession number X).

\section{Statistical Analysis}

Data were analyzed using Microsoft Excel (Microsoft) and Graphpad Prism (GraphPad Software). All FACS analyses were performed using Flowjo software (TreeStar). 


\section{ACKNOWLEDGMENTS}

We thank Gerd Sten for expert technical support and Martin Wahlestedt for assistance with manuscript editing. The work was aided by the access to the StemTherapy funded core facilities in Bioinformatics and flow cytometry. This work was supported by grants from the Tobias Foundation, the Swedish Cancer Society, the Swedish Medical Research Council, the Knut and Alice Wallenberg foundation and an ERC Consolidator grant (615068) to D.B.

\section{AUTHOR CONTRIBUTIONS}

PS, ME, EE, TAK, CL conducted experiments. SS managed sequencing data. ZK, JY provided key input on fetal derived subsets and in the design of experiments connected to this. GK provided input on the characterization of LSKCD $150^{+} \mathrm{CD}_{48}{ }^{+}$cells. PKM and DJR provided key reagents, advice on mouse model and discussions on the overall study design with PS and DB. DB conceived and supervised the study and, together with PS, designed experiments and wrote the manuscript.

\section{CONFLICT OF INTEREST DISCLOSURE}

The authors declare no competing financial interests. 


\section{REFERENCES}

Acar, M., Kocherlakota, K. S., Murphy, M. M., Peyer, J. G., Oguro, H., Inra, C. N., . . Morrison, S. J. (2015). Deep imaging of bone marrow shows non-dividing stem cells are mainly perisinusoidal. Nature, 526(7571), 126-130. doi:10.1038/nature15250

Adolfsson, J., Månsson, R., Buza-Vidas, N., Hultquist, A., Liuba, K., Jensen, C. T., . . . Jacobsen, S. E. (2005). Identification of Flt3+ lympho-myeloid stem cells lacking erythro-megakaryocytic potential a revised road map for adult blood lineage commitment. Cell, 121(2), 295-306. doi:10.1016/j.cell.2005.02.013

Akashi, K., Traver, D., Miyamoto, T., \& Weissman, I. L. (2000). A clonogenic common myeloid progenitor that gives rise to all myeloid lineages. Nature, 404(6774), 193-197. doi:10.1038/35004599

Alliot, F., Godin, I., \& Pessac, B. (1999). Microglia derive from progenitors, originating from the yolk sac, and which proliferate in the brain. Brain Res Dev Brain Res, 117(2), 145-152.

Arinobu, Y., Mizuno, S., Chong, Y., Shigematsu, H., Iino, T., Iwasaki, H., . . Akashi, K. (2007). Reciprocal activation of GATA-1 and PU.1 marks initial specification of hematopoietic stem cells into myeloerythroid and myelolymphoid lineages. Cell Stem Cell, 1(4), 416-427. doi:10.1016/j.stem.2007.07.004

Atkins, H. L., Bowman, M., Allan, D., Anstee, G., Arnold, D. L., Bar-Or, A., . . . Freedman, M. S. (2016). Immunoablation and autologous haemopoietic stem-cell transplantation for aggressive multiple sclerosis: a multicentre single-group phase 2 trial. Lancet, 388(10044), 576-585. doi:10.1016/S0140-6736(16)30169-6

Bando, J. K., \& Colonna, M. (2016). Innate lymphoid cell function in the context of adaptive immunity. Nat Immunol, 17(7), 783-789. doi:10.1038/ni.3484

Benz, C., Copley, M. R., Kent, D. G., Wohrer, S., Cortes, A., Aghaeepour, N., . . Eaves, C. J. (2012). Hematopoietic stem cell subtypes expand differentially during development and display distinct lymphopoietic programs. Cell Stem Cell, 10(3), 273-283. doi:10.1016/j.stem.2012.02.007

Biasco, L., Pellin, D., Scala, S., Dionisio, F., Basso-Ricci, L., Leonardelli, L., . . A Aiuti, A. (2016). In Vivo Tracking of Human Hematopoiesis Reveals Patterns of Clonal Dynamics during Early and Steady-State Reconstitution Phases. Cell Stem Cell, 19(1), 107-119. doi:10.1016/j.stem.2016.04.016

Bowie, M. B., Kent, D. G., Dykstra, B., McKnight, K. D., McCaffrey, L., Hoodless, P. A., \& Eaves, C. J. (2007). Identification of a new intrinsically timed developmental checkpoint that reprograms key hematopoietic stem cell properties. Proc Natl Acad Sci $U$ S A, 104(14), 5878-5882. doi:10.1073/pnas.0700460104

Bryder, D., Rossi, D. J., \& Weissman, I. L. (2006). Hematopoietic stem cells: the paradigmatic tissue-specific stem cell. Am J Pathol, 169(2), 338-346. doi:10.2353/ajpath.2006.060312

Busch, K., Klapproth, K., Barile, M., Flossdorf, M., Holland-Letz, T., Schlenner, S. M., . . Rodewald, H. R. (2015). Fundamental properties of unperturbed 
haematopoiesis from stem cells in vivo. Nature, 518(7540), 542-546. doi:10.1038/nature 14242

Chen, J. Y., Miyanishi, M., Wang, S. K., Yamazaki, S., Sinha, R., Kao, K. S., . . . Weissman, I. L. (2016). Hoxb5 marks long-term haematopoietic stem cells and reveals a homogenous perivascular niche. Nature, 530(7589), 223227. doi:10.1038/nature 16943

Chen, Q., Ye, W., Jian Tan, W., Mei Yong, K. S., Liu, M., Qi Tan, S., ... Chen, J. (2015). Delineation of Natural Killer Cell Differentiation from Myeloid Progenitors in Human. Sci Rep, 5, 15118. doi:10.1038/srep15118

Cheng, C., Haasdijk, R., Tempel, D., van de Kamp, E. H., Herpers, R., Bos, F., . . . Duckers, H. J. (2012). Endothelial cell-specific FGD5 involvement in vascular pruning defines neovessel fate in mice. Circulation, 125(25), 3142-3158. doi:10.1161/CIRCULATIONAHA.111.064030

Collin, M., \& Milne, P. (2016). Langerhans cell origin and regulation. Curr Opin Hematol, 23(1), 28-35. doi:10.1097/MOH.0000000000000202

Drissen, R., Buza-Vidas, N., Woll, P., Thongjuea, S., Gambardella, A., Giustacchini, A., . . . Nerlov, C. (2016). Distinct myeloid progenitor-differentiation pathways identified through single-cell RNA sequencing. Nat Immunol, 17(6), 666-676. doi:10.1038/ni.3412

Dykstra, B., Kent, D., Bowie, M., McCaffrey, L., Hamilton, M., Lyons, K., ... Eaves, C. (2007). Long-term propagation of distinct hematopoietic differentiation programs in vivo. Cell Stem Cell, 1(2), 218-229. doi:10.1016/j.stem.2007.05.015

Dzierzak, E., \& Philipsen, S. (2013). Erythropoiesis: development and differentiation. Cold Spring Harb Perspect Med, 3(4), a011601. doi:10.1101/cshperspect.a011601

Galli, S. J., Borregaard, N., \& Wynn, T. A. (2011). Phenotypic and functional plasticity of cells of innate immunity: macrophages, mast cells and neutrophils. Nat Immunol, 12(11), 1035-1044. doi:10.1038/ni.2109

Gazit, R., Mandal, P. K., Ebina, W., Ben-Zvi, A., Nombela-Arrieta, C., Silberstein, L. E., \& Rossi, D. J. (2014). Fgd5 identifies hematopoietic stem cells in the murine bone marrow. J Exp Med, 211(7), 1315-1331. doi:10.1084/jem.20130428

Ginhoux, F., \& Guilliams, M. (2016). Tissue-Resident Macrophage Ontogeny and Homeostasis. Immunity, 44(3), 439-449. doi:10.1016/j.immuni.2016.02.024

Grzywacz, B., Kataria, N., Blazar, B. R., Miller, J. S., \& Verneris, M. R. (2011). Natural killer-cell differentiation by myeloid progenitors. Blood, 117(13), 3548-3558. doi:10.1182/blood-2010-04-281394

Harker, L. A., Roskos, L. K., Marzec, U. M., Carter, R. A., Cherry, J. K., Sundell, B., . . Sheridan, W. (2000). Effects of megakaryocyte growth and development factor on platelet production, platelet life span, and platelet function in healthy human volunteers. Blood, 95(8), 2514-2522.

Havran, W. L., \& Allison, J. P. (1990). Origin of Thy-1+ dendritic epidermal cells of adult mice from fetal thymic precursors. Nature, 344(6261), 68-70. doi:10.1038/344068a0

Hayakawa, K., Hardy, R. R., \& Herzenberg, L. A. (1985). Progenitors for Ly-1 B cells are distinct from progenitors for other B cells. J Exp Med, 161(6), 1554-1568. 
Kantor, A. B., Stall, A. M., Adams, S., Watanabe, K., \& Herzenberg, L. A. (1995). De novo development and self-replenishment of B cells. Int Immunol, 7(1), 55-68.

Kiel, M. J., Yilmaz, O. H., Iwashita, T., Terhorst, C., \& Morrison, S. J. (2005). SLAM family receptors distinguish hematopoietic stem and progenitor cells and reveal endothelial niches for stem cells. Cell, 121(7), 1109-1121. doi:10.1016/j.cell.2005.05.026

Kiel, M. J., Yilmaz, O. H., \& Morrison, S. J. (2008). CD150- cells are transiently reconstituting multipotent progenitors with little or no stem cell activity. Blood, 111(8), 4413-4414; author reply 4414-4415. doi:10.1182/blood2007-12-129601

Lu, R., Neff, N. F., Quake, S. R., \& Weissman, I. L. (2011). Tracking single hematopoietic stem cells in vivo using high-throughput sequencing in conjunction with viral genetic barcoding. Nat Biotechnol, 29(10), 928-933. doi:10.1038/nbt.1977

Madisen, L., Zwingman, T. A., Sunkin, S. M., Oh, S. W., Zariwala, H. A., Gu, H., . . Zeng, H. (2010). A robust and high-throughput Cre reporting and characterization system for the whole mouse brain. Nat Neurosci, 13(1), 133-140. doi:10.1038/nn.2467

Morrison, S. J., Wandycz, A. M., Akashi, K., Globerson, A., \& Weissman, I. L. (1996). The aging of hematopoietic stem cells. Nat Med, 2(9), 1011-1016.

Nilsson, A. R., Pronk, C. J., \& Bryder, D. (2015). Probing hematopoietic stem cell function using serial transplantation: Seeding characteristics and the impact of stem cell purification. Exp Hematol. doi:10.1016/j.exphem.2015.05.003

Oguro, H., Ding, L., \& Morrison, S. J. (2013). SLAM family markers resolve functionally distinct subpopulations of hematopoietic stem cells and multipotent progenitors. Cell Stem Cell, 13(1), 102-116. doi:10.1016/j.stem.2013.05.014

Palchaudhuri, R., Saez, B., Hoggatt, J., Schajnovitz, A., Sykes, D. B., Tate, T. A., . . Scadden, D. T. (2016). Non-genotoxic conditioning for hematopoietic stem cell transplantation using a hematopoietic-cell-specific internalizing immunotoxin. Nat Biotechnol, 34(7), 738-745. doi:10.1038/nbt.3584

Paul, F., Arkin, Y., Giladi, A., Jaitin, D. A., Kenigsberg, E., Keren-Shaul, H., . . Amit, I. (2015). Transcriptional Heterogeneity and Lineage Commitment in Myeloid Progenitors. Cell, 163(7), 1663-1677. doi:10.1016/j.cell.2015.11.013

Pietras, E. M., Reynaud, D., Kang, Y. A., Carlin, D., Calero-Nieto, F. J., Leavitt, A. D., . . . Passegué, E. (2015). Functionally Distinct Subsets of Lineage-Biased Multipotent Progenitors Control Blood Production in Normal and Regenerative Conditions. Cell Stem Cell, 17(1), 35-46. doi:10.1016/j.stem.2015.05.003

Pronk, C. J., Rossi, D. J., Månsson, R., Attema, J. L., Norddahl, G. L., Chan, C. K., . . . Bryder, D. (2007). Elucidation of the phenotypic, functional, and molecular topography of a myeloerythroid progenitor cell hierarchy. Cell Stem Cell, 1(4), 428-442. doi:10.1016/j.stem.2007.07.005

Rodvien, R., \& Mielke, C. H. (1976). Role of platelets in hemostasis and thrombosis. West J Med, 125(3), 181-186. 
Rossi, D. J., Bryder, D., Zahn, J. M., Ahlenius, H., Sonu, R., Wagers, A. J., \& Weissman, I. L. (2005). Cell intrinsic alterations underlie hematopoietic stem cell aging. Proc Natl Acad Sci U S A, 102(26), 9194-9199. doi:10.1073/pnas.0503280102

Sanjuan-Pla, A., Macaulay, I. C., Jensen, C. T., Woll, P. S., Luis, T. C., Mead, A., . . Jacobsen, S. E. (2013). Platelet-biased stem cells reside at the apex of the haematopoietic stem-cell hierarchy. Nature, 502(7470), 232-236. doi:10.1038/nature 12495

Sawai, C. M., Babovic, S., Upadhaya, S., Knapp, D. J., Lavin, Y., Lau, C. M., . . Reizis, B. (2016). Hematopoietic Stem Cells Are the Major Source of Multilineage Hematopoiesis in Adult Animals. Immunity, 45(3), 597-609. doi:10.1016/j.immuni.2016.08.007

Shin, J. Y., Hu, W., Naramura, M., \& Park, C. Y. (2014). High c-Kit expression identifies hematopoietic stem cells with impaired self-renewal and megakaryocytic bias. J Exp Med, 211(2), 217-231. doi:10.1084/jem.20131128

Siminovitch, L., McCulloch, E. A., \& Till, J. E. (1963). The distribution of colonyforming cells among spleen colonies. J Cell Comp Physiol, 62, 327-336.

Sudo, K., Ema, H., Morita, Y., \& Nakauchi, H. (2000). Age-associated characteristics of murine hematopoietic stem cells. J Exp Med, 192(9), 1273-1280.

Sun, J., Ramos, A., Chapman, B., Johnnidis, J. B., Le, L., Ho, Y. J., . . Camargo, F. D. (2014). Clonal dynamics of native haematopoiesis. Nature, 514(7522), 322-327. doi:10.1038/nature13824

Säwén, P., Lang, S., Mandal, P., Rossi, D. J., Soneji, S., \& Bryder, D. (2016). Mitotic History Reveals Distinct Stem Cell Populations and Their Contributions to Hematopoiesis. Cell Rep, 14(12), 2809-2818. doi:10.1016/j.celrep.2016.02.073

Till, J. E., \& McCulloch , E. A. (1961). A direct measurement of the radiation sensitivity of normal mouse bone marrow cells. Radiat Res, 14, 213-222.

Ugale, A., Norddahl, G. L., Wahlestedt, M., Säwén, P., Jaako, P., Pronk, C. J., . . . Bryder, D. (2014). Hematopoietic stem cells are intrinsically protected against MLL-ENL-mediated transformation. Cell Rep, 9(4), 1246-1255. doi:10.1016/j.celrep.2014.10.036

Van Putten, L. M. (1958). The life span of red cells in the rat and the mouse as determined by labeling with DFP32 in vivo. Blood, 13(8), 789-794.

Velten, L., Haas, S. F., Raffel, S., Blaszkiewicz, S., Islam, S., Hennig, B. P., . . . Steinmetz, L. M. (2017). Human haematopoietic stem cell lineage commitment is a continuous process. Nat Cell Biol, 19(4), 271-281. doi:10.1038/ncb3493

Weksberg, D. C., Chambers, S. M., Boles, N. C., \& Goodell, M. A. (2008). CD150side population cells represent a functionally distinct population of longterm hematopoietic stem cells. Blood, 111(4), 2444-2451. doi:10.1182/blood-2007-09-115006

Westera, L., Drylewicz, J., den Braber, I., Mugwagwa, T., van der Maas, I., Kwast, L., . . . Borghans, J. A. (2013). Closing the gap between T-cell life span estimates from stable isotope-labeling studies in mice and humans. Blood, 122(13), 2205-2212. doi:10.1182/blood-2013-03-488411 
Wilson, A., Laurenti, E., Oser, G., van der Wath, R. C., Blanco-Bose, W., Jaworski, M., . . . Trumpp, A. (2008). Hematopoietic stem cells reversibly switch from dormancy to self-renewal during homeostasis and repair. Cell, 135(6), 1118-1129. doi:10.1016/j.cell.2008.10.048

Wu, C., Li, B., Lu, R., Koelle, S. J., Yang, Y., Jares, A., . . Dunbar, C. E. (2014). Clonal tracking of rhesus macaque hematopoiesis highlights a distinct lineage origin for natural killer cells. Cell Stem Cell, 14(4), 486-499. doi:10.1016/j.stem.2014.01.020 


\section{FIGURE LEGENDS}

Figure 1. Fgd5-CreERT2 specifically labels HSCs and Fgd5-mediated label progresses throughout the hematopoietic system. (A) Lineage negative c-kit ${ }^{+}$cells (Linc-kit ${ }^{+}$, left), lineage negative c-kit ${ }^{+} \mathrm{Fgd5}^{+}$cells $\left(\mathrm{Fgd5}^{+}\right.$, middle) and lineage negative $\mathrm{Fgd} 5^{+} \mathrm{C}-\mathrm{kit}^{+} \mathrm{Sca}-{ }^{+} \mathrm{CD} 150^{+} \mathrm{CD} 48^{-},\left(\mathrm{HSC}-\mathrm{Fgd} 5^{+}\right.$, right) were individually isolated and their transcriptomes determined by RNAseq. The data was aggregated and visualized in a two-dimensional scatter plot after PCA and tSNE dimensionality reduction. Fgd5 ${ }^{+}$cells are highlighted in pink (middle), Lin ${ }^{-}$-kit ${ }^{+}$cells are highlighted in black (left plot) and HSC$\mathrm{Fgd}^{+}$cells are highlighted in blue (right plot). The area that $\mathrm{Fgd5}^{+}$cells occupy in relation to the transcriptomes of Linc-kit $^{+}$cells and $\mathrm{HSC}-\mathrm{Fgd}^{+}$cells is marked by a dotted line (left and right plots). (B) Schematic representation of the Fgd5 ${ }^{\text {CreERT2/+ }}$ Rosa26 $6^{\text {Tomato/+ }}$ model. ZsGreen and CreERT2 are expressed from the Fgd5 locus and expression of a Tomato allele is driven by a CAG promoter from the Rosa26 locus and is preceded by a LoxP flanked STOP cassette. (C) Model description; HSCs selectively and continuously express ZsGreen. Upon Tamoxifen (TAM) administration, HSCs express Tomato and expression of Tomato label is inherited by all progeny of Tomatoexpressing HSCs. (D) Representative FACS plots showing Tomato label in BM HSPCs from Fgd5 ${ }^{\text {CreERT2/+ }}$ Rosa26 $6^{\text {Tomato/+ }}$ mice that were injected with Tamoxifen 48 hours prior to analysis. (D, lower right) Representative histograms depicting Tomato label in PB cells at various time points after the start of Tamoxifen administration from mice in Fig. 3B ( $T$ cells 48 weeks, B cells 25 weeks, granulocytes and monocytes 8 weeks, platelets and 
erythrocytes 13 weeks). Numbers in FACS plots depict the mean \% of Tomato labeled cells \pm SD $(n=5)$ and dashed lines in histograms indicates the boundary for Tomato positivity. (E) FACS plots showing H2B-mCherry label retention and Tomato labeling in Lineage ${ }^{-} \mathrm{c}-\mathrm{kit}^{+} \mathrm{CD} 150^{+} \mathrm{CD} 48^{-}$and $\mathrm{Sca}^{+}{ }^{+}$or Sca1 ${ }^{-}$cells from a representative mouse that had diluted H2B-mCherry label for 5 weeks and were injected with Tamoxifen 5 days prior to analysis $(n=3)$. (F) The fraction of donor-derived cells among different blood cell lineages assessed in individual mice 16 weeks post-transplantation in recipients of 5 Tomato $^{+}(\mathrm{n}=8)$ or 5 Tomato $^{-}(\mathrm{n}=7)$ HSCs. Abbreviations: $2 \mathrm{~A}, 2 \mathrm{~A}$ selfcleaving peptide; CAG, CAG promoter; loxP, LoxP site.

Figure 2. Fgd5-CreERT2 mediated lineage tracing reveals robust HSC contribution with distinct kinetics into hematopoietic cell subsets in steady state and after transplantation. Cohorts of Fgd5 ${ }^{\text {CreERT2/+ }}$ Rosa26 ${ }^{\text {Tomato/+ }}$ mice were chased for up to 83 weeks after receiving one Tamoxifen injection before endpoint analysis of the \% of Tomato $^{+}$cells in HSCs (A) and hematopoietic progenitor and PB cell subsets (B). The fraction of Tomato ${ }^{+}$cells in each indicated hematopoietic cell subset was divided by the \% Tomato label in HSCs in corresponding mice to determine the ratio of Tomato $^{+}$cells relative to HSCs in individual mice. The average ratio is plotted according to time after the Tamoxifen (TAM) injection analysis and displayed in a heat map format. Mice were analyzed at 1-4 days $(n=18)$ and at $4(n=7), 8(n=8), 12(n=8), 16(n=4), 28(n=4), 32(n=5)$ and $83(n=3)$ weeks after the Tamoxifen injection. (C) PCA plot of multiplexed qRT-PCR data for 48 genes from triplicates of 10 cells from each of the 
indicated populations. Ellipses show an area where a new observation from the same group would position itself with a probability of 0.95 . Numbers indicate the \% of variance in the total data set that the respective PC explains. (D) For individual animals, the $\%$ of Tomato $^{+}$cells in PB cell types was divided by the $\%$ of Tomato ${ }^{+}$cells in the indicated progenitor cell types and this value was plotted according to the duration of the chase period. Symbols represent individual mice (number of mice analyzed as in $A$ and $B$ ). A dashed line is drawn to indicate an equilibrium-ratio of 1. (E) Ratios calculated as in B and plotted according to the number of weeks after transplantation or after the start of Tamoxifen administration for steady state/native mice ( $n=3$ for WBM tx in CD45 depleted, $n=5$ for WBM tx in irradiated, $n=11$ for HSC tx in irradiated, $n=4-8$ for $1 x$ TAM, $n=4-9$ for continous TAM).

Figure 3. Fgd5-mediated lineage tracing after complete HSC labeling reveals limited adult HSCs contribution to tissue-resident immune cell subsets. (A) H2B-mCherry label retention in HSCs and myeloid progenitors after 5 weeks of chase in mice continuously fed Tamoxifen (TAM) containing food (blue histograms, $n=7$ ) or normal food (red histograms, $n=6$ ) during the chase period. Green histograms depict an unlabeled control. Dashed lines indicate the boundary for H2B-mCherry positivity. Lineage negative ckit $^{+}$Sca1 ${ }^{-}$cells are denoted as myeloid progenitors. (B) Cohorts of Fgd5 ${ }^{\text {CreERT2/+ }}$ Rosa26 ${ }^{\text {Tomato/+ }}$ mice were continuously fed Tamoxifen food for 16 weeks (TAM phase) and thereafter normal chow during a chase phase of 32 weeks $(n=5)$ or 41 weeks $(n=4)$. During the TAM and chase phases, PB 
was regularly analyzed for Tomato label in the indicated subsets. Data points indicate the average \% of Tomato label in each indicated subset. (C-E) Endpoint analysis, after 41 weeks chase, in mice from Fig. $3 B(n=3)$. (C) Representative FACS plots showing the gating strategy to identify HSCs in lineage negative BM cells (left, middle) and depiction of the Tomato label in HSCs (right, red histogram) compared to an unlabeled control (blue histogram). Dashed line indicates the boundary for Tomato positivity, arrows indicate the gating strategy. (D) Representative FACS plots of cells isolated from skin tissue (epidermis) or the peritoneal cavity. Histograms show Tomato label (bottom left and right) or ZsGreen label (bottom middle) in the indicated subsets. Dashed line indicate the boundary for Tomato positivity, arrows indicate the gating hierarchy, gates and corresponding histograms are color matched. (E) Representative confocal images of the brain. (Left) IBA1 positive cells (green) are not labeled with Tomato (red, middle) while blood vessels are labeled with Tomato (middle). (Right) Merged images display both IBA1 staining and Tomato label. Scale bar $=50 \mu \mathrm{m}$.

Figure 4. Fgd5 mediate lineage tracing reveals gradually declining HSC contribution to hematopoiesis with age. (A) Cohorts of aged (11-12 months; $\mathrm{n}=3$ ) or young $(23-25$ days; $\mathrm{n}=5,) \mathrm{Fgd5} 5^{\mathrm{CreERT} 2 /+}$ Rosa26 ${ }^{\text {Tomato/+ }}$ mice were injected with Tamoxifen 5 times on consecutive days and analyzed for Tomato label in LSK-HSPCs on day 6. Bars indicate median \%. (B) Fgd5 ${ }^{\text {CreERT2/+ }}$ Rosa26 ${ }^{\text {Tomato/t }}$ mice were injected with Tamoxifen for 5 consecutive days and analyzed for Tomato label in LSK-HSPCs 21 days later. 
The $\%$ of Tomato $^{+}$cells in $\mathrm{MPP}^{2-4}$ was divided by the $\%$ of Tomato ${ }^{+} \mathrm{HSC}$ in corresponding mice to determine the ratio of Tomato $^{+}$cells relative to HSCs. Ratios are plotted according to the age of mice at the time of Tamoxifen injection. (C) Indicated LSK subsets were isolated from Fgd5 ${ }^{\text {CreERT2/+ }}$ Rosa26 ${ }^{\text {Tomato/+ }}$ mice and transplanted into WT mice on continuous Tamoxifen. Multilineage hematopoiesis and Tomato contribution was assed in PB 4, 8, 12 and 16 weeks after transplantation. Values in parenthesis indicate the number of mice with Tomato+ offspring. (D) Young (29 days; $n=3$ ) and old (16 months; n=4) Fgd5 ${ }^{\mathrm{CreERT} /{ }^{2}}$ Rosa26 $6^{\text {Tomato/+ }}$ mice were injected once with Tamoxifen and analyzed for Tomato label 18 weeks later. The \% of Tomato ${ }^{+}$ cells in each indicated cell type was divided by the $\%$ of Tomato ${ }^{+} \mathrm{HSC}$ in corresponding mice to determine the ratio of Tomato $^{+}$cells relative to HSCs. (E) Model depicting HSC contribution to native hematopoiesis. Arrow weights and arrow lengths indicate the magnitude and the kinetics of HSC contribution to the indicated cell type respectively. The declining HSC contribution to hematopoiesis with age can be traced to a reduced differentiation of HSCs to MPPs (red arrows). 
bioRxiv preprint doi: https://doi.org/10.1101/415323; this version posted September 12, 2018. The copyright holder for this preprint (which was not certified by peer review) is the author/funder, who has granted bioRxiv a license to display the preprint in perpetuity. It is made available under aCC-BY 4.0 International license.

A

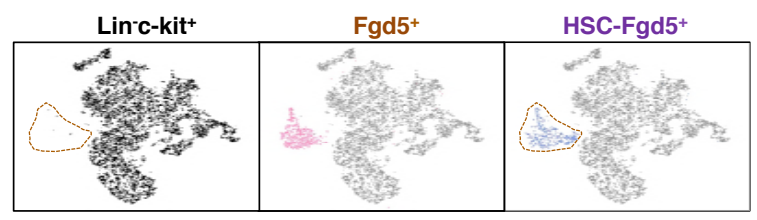

B

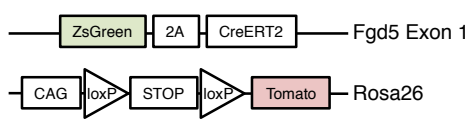

C no tAM No chase $\begin{array}{cc}\text { TAM } & \text { TAM } \\ \text { Chase }\end{array}$

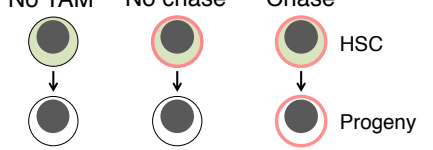

D

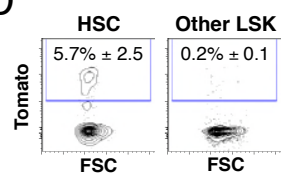

E Lineage negative
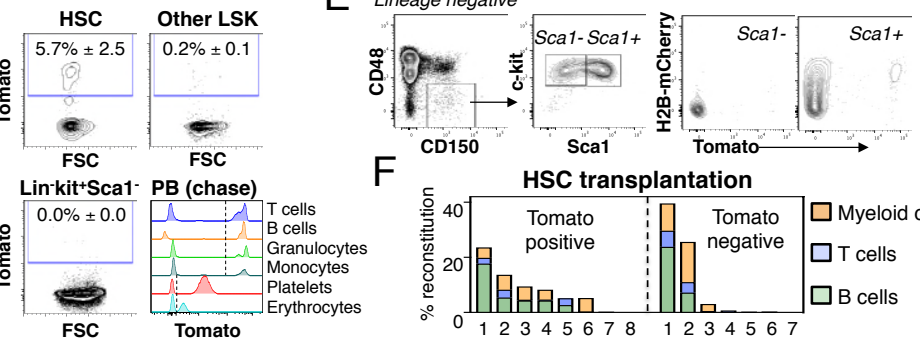

$\mathrm{F}$

HSC transplantation

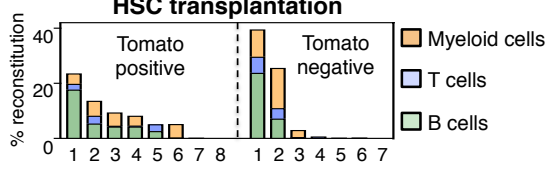

Figure 1, Säwén et al

A

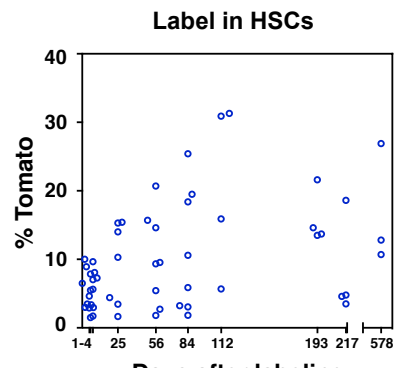

C

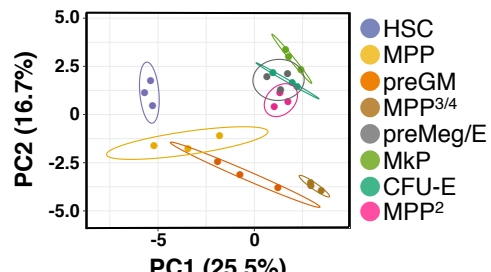

D

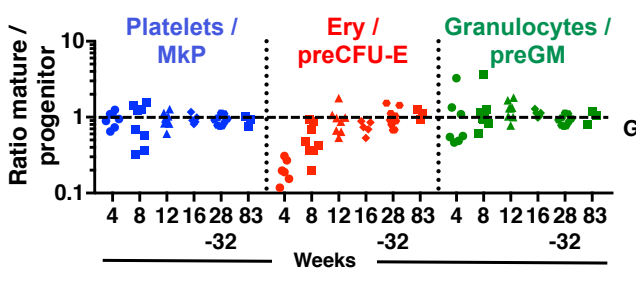

B

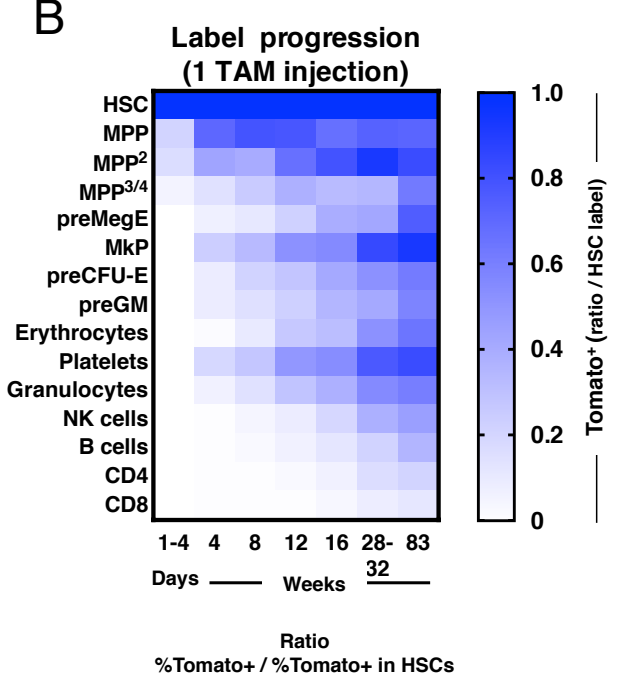

E $\underset{\text { in CD45 }}{\text { WBM } x} \underset{\text { tx in }}{\text { WBM }} \quad \underset{\text { tx in }}{\text { HSC }} \quad \frac{\text { Steady State }}{\text { Continous }}$

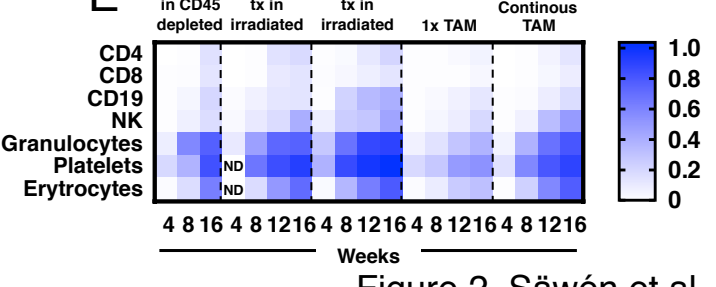

Figure 2, Säwén et al 
bioRxiv preprint doi: https://doi.org/10.1101/415323; this version posted September 12, 2018. The copyright holder for this preprint (which was not certified by peer review) is the author/funder, who has granted bioRxiv a license to display the preprint in perpetuity. It is made available under aCC-BY 4.0 International license.

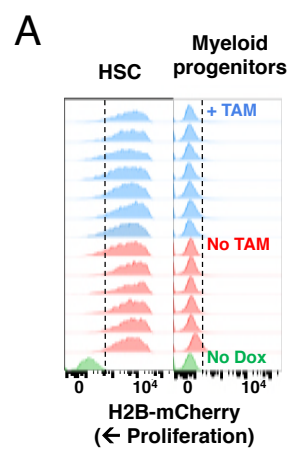

C

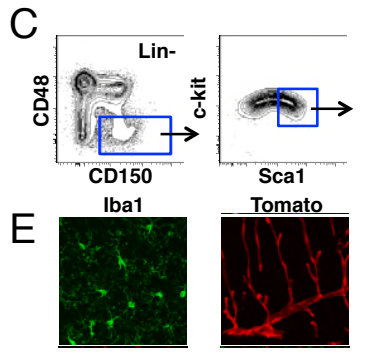

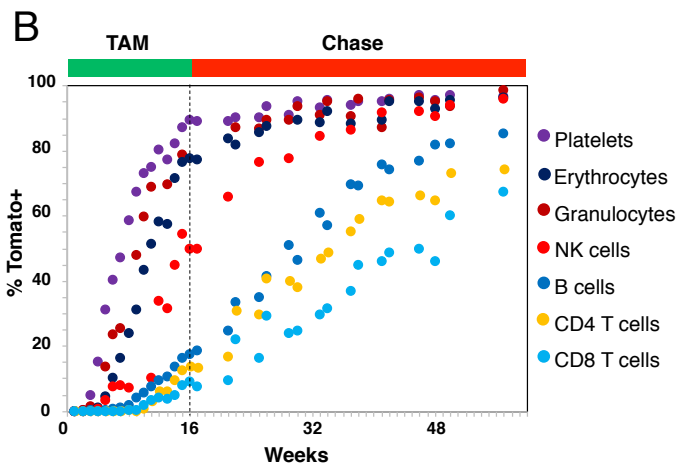

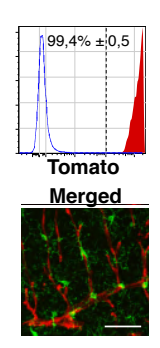

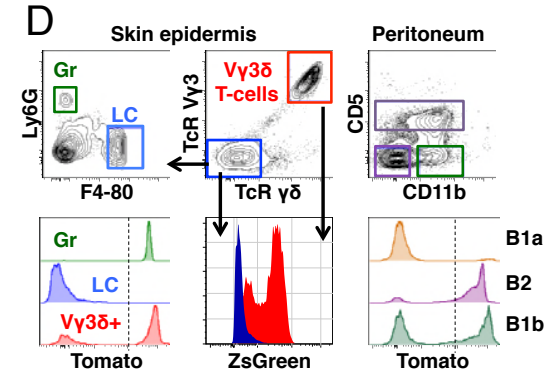

Figure 3, Säwén et al

A
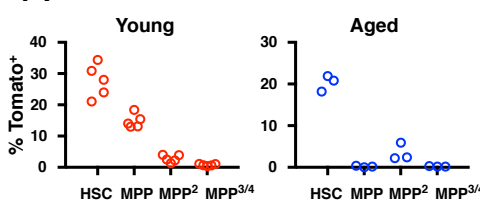

B

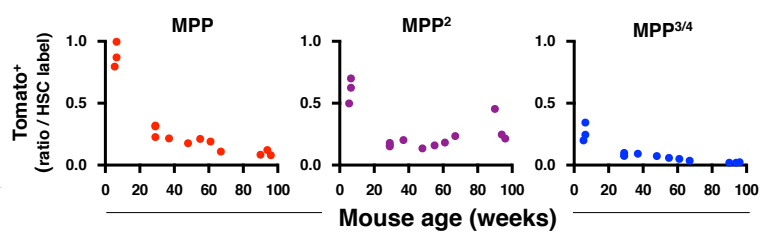

C

\begin{tabular}{|c|c|c|c|c|}
\hline \multirow{2}{*}{ Fraction } & \multirow{2}{*}{$\begin{array}{l}\text { Cell } \\
\text { dose }\end{array}$} & \multicolumn{2}{|c|}{ Long-term } & \multirow{2}{*}{$\begin{array}{l}\text { Transient } \\
\text { Myeloid }\end{array}$} \\
\hline & & Multi lineage & Lymphoid only & \\
\hline HSC & 200 & $10 / 10(10)$ & $0 / 10(0)$ & $0 / 10(0)$ \\
\hline MPP & 635 & 2/9 (2) & $7 / 9(0)$ & $7 / 9(0)$ \\
\hline MPP2 & 1200 & $0 / 5(0)$ & $0 / 5(0)$ & $4 / 5(0)$ \\
\hline $\mathrm{MPP}^{3 / 4}$ & 7300 & $0 / 4(0)$ & $4 / 4(0)$ & $4 / 4(0)$ \\
\hline
\end{tabular}

E
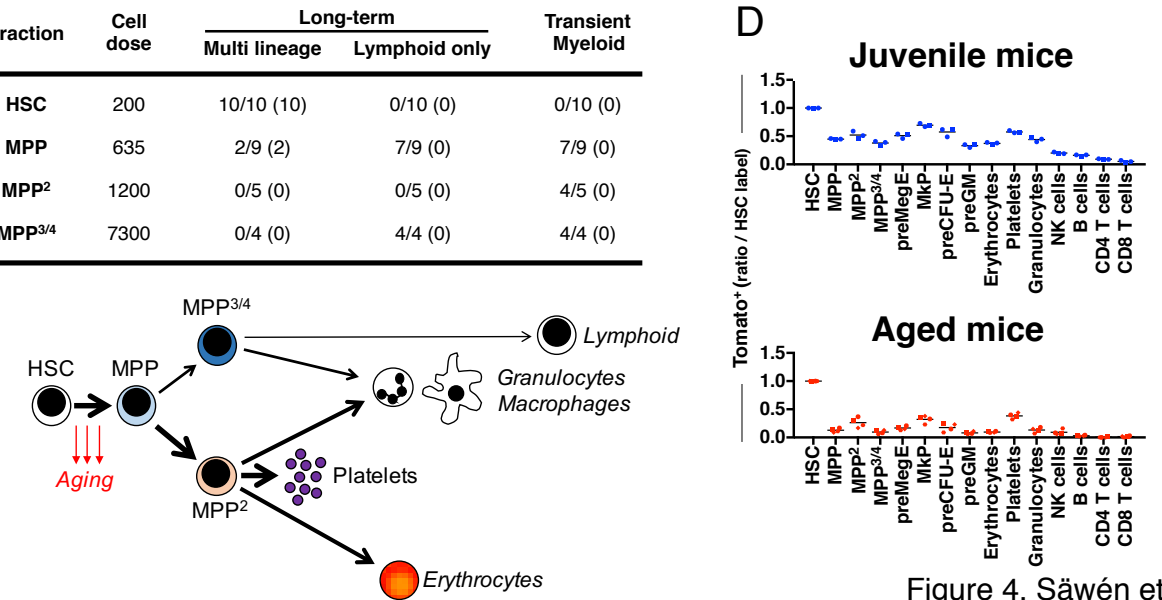

Figure 4, Säwén et al 


\section{Supplementary Information for}

\section{Hematopoietic Stem Cells Contribute Actively to Native Murine Hematopoiesis but Exhibit Diminished Differentiation Capacity With Age}

Petter Säwén ${ }^{a}$, Mohamed Eldeeb ${ }^{a}$, Eva Erlandsson ${ }^{a}$, Trine A Kristiansen ${ }^{a}$, Cecilia Laterza $^{\mathrm{d}, \mathrm{e}}$, Zaal Kokaia ${ }^{\mathrm{d}, \mathrm{e}}$, Göran Karlsson ${ }^{\mathrm{a}, \mathrm{d}, \mathrm{e}}$, Joan Yuan ${ }^{\mathrm{a}, \mathrm{d}, \mathrm{e}}$, Shamit Soneji ${ }^{\mathrm{a}, \mathrm{d}, \mathrm{e}}$, Pankaj K. Mandal ${ }^{\mathrm{b}, \mathrm{c}}$, Derrick J Rossi ${ }^{\mathrm{b}, \mathrm{c}}$ and David Bryder ${ }^{\mathrm{a}, \mathrm{d}, \mathrm{e}, \mathrm{f}}$

${ }^{a}$ Lund University, Medical Faculty, Department of Laboratory Medicine, Division of Molecular Hematology, Klinikgatan 26, BMC B12, 221 84, Lund, Sweden

${ }^{\mathrm{b}}$ Department of Stem Cell and Regenerative Biology, Harvard University, Cambridge, MA 02138, USA

${ }^{\mathrm{C}}$ Program in Cellular and Molecular Medicine, Division of Hematology/Oncology, Boston Children's Hospital, MA 02116, USA

${ }^{d}$ StemTherapy, Lund University

${ }^{e}$ Lund Stem Cell Center, Lund University

${ }^{f}$ Sahlgrenska Cancer Center, Gothenburg University

Corresponding author: David Bryder

Email: David.Bryder@med.lu.se

This file includes:

Figs. $\mathrm{S} 1$ to $\mathrm{S} 4$

Tables S1 to S2 


\section{A}

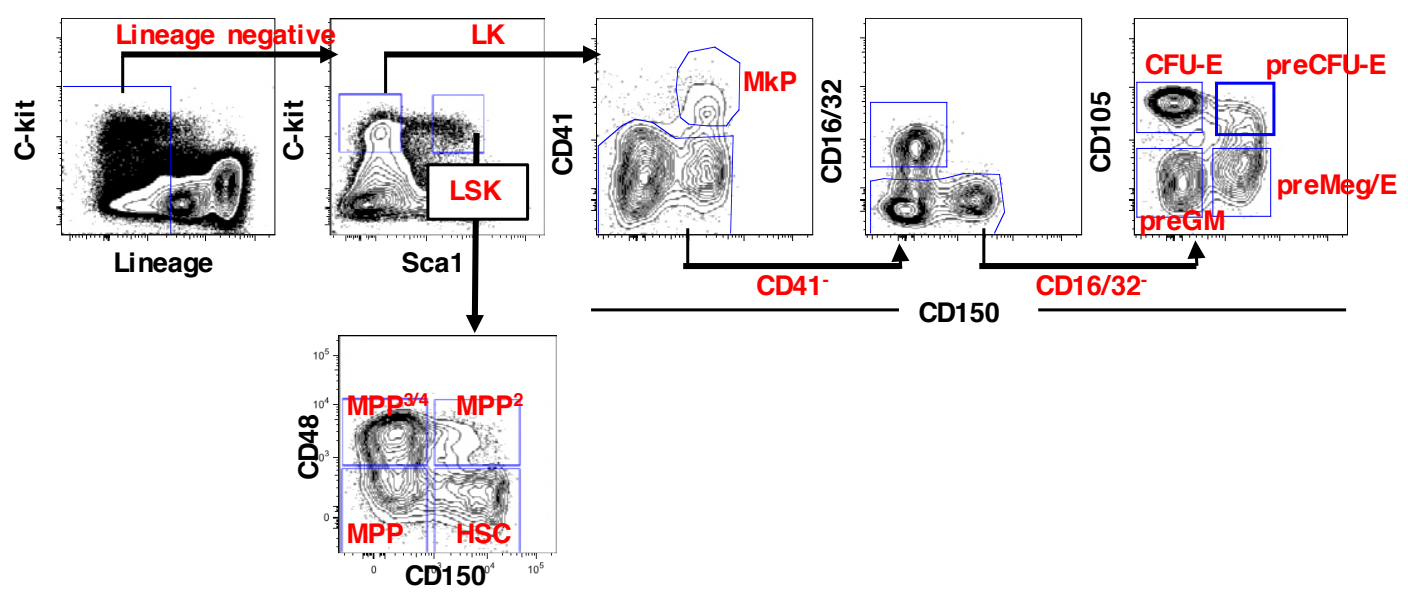

B
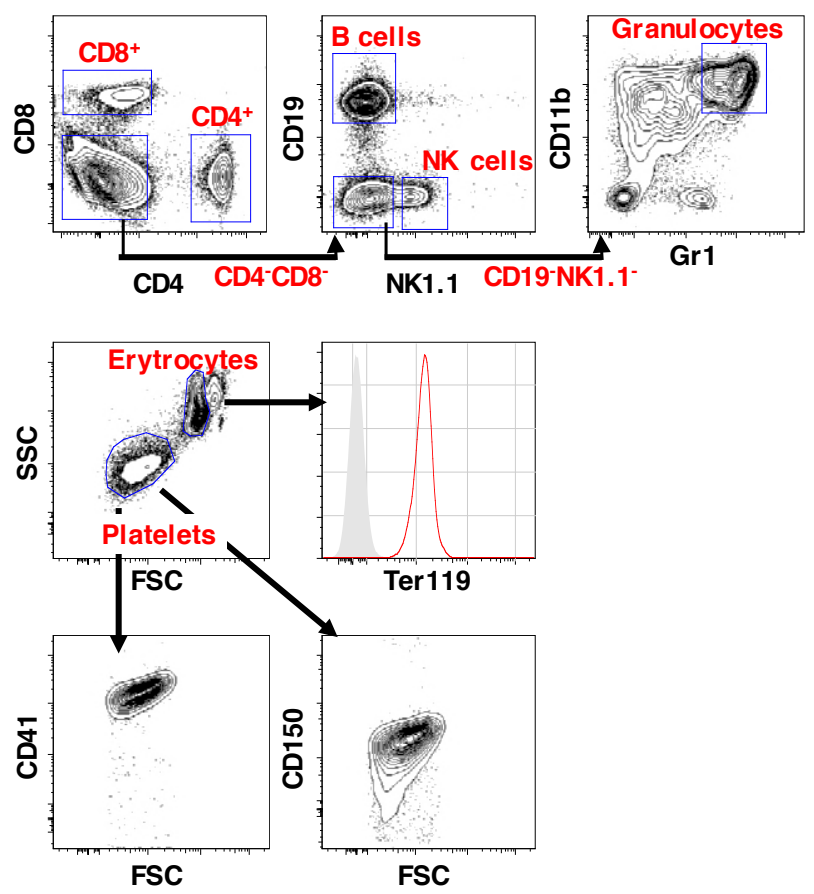

Fig. S1. FACS gating strategies for identification of hematopoietic subsets. (A) The gating scheme for identification of HSCs/MPPs and myeloerythroid progenitors within the LSK and LK populations, respectively. (B) The gating scheme for identification of peripheral blood subsets. Red histogram display Ter119 expression in erythrocytes over an unlabeled control (grey histogram) and platelets identified by gating on scatter characteristics display expression of both CD41 and CD150. 

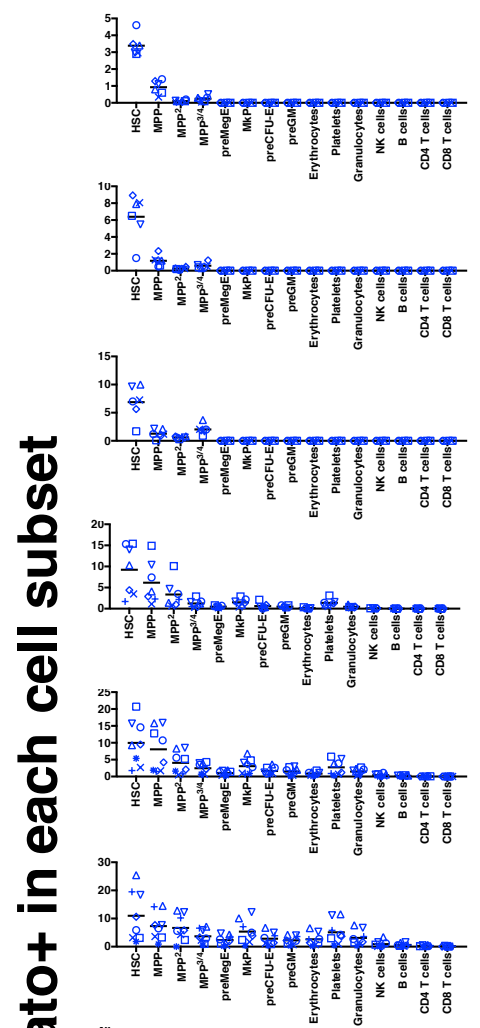

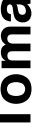
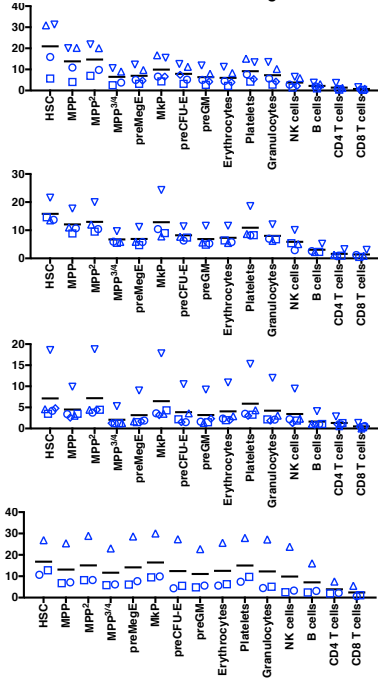

24 hours

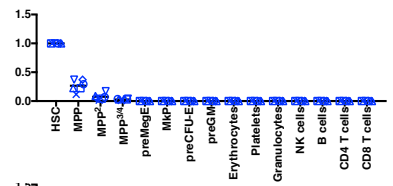

48 hours

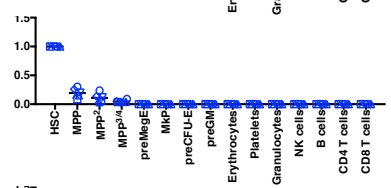

96 hours

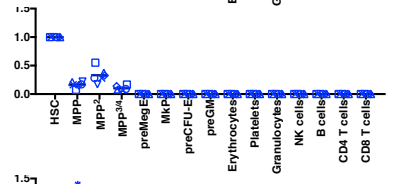

4 weeks

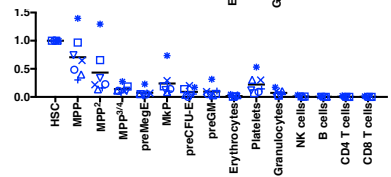

8 weeks

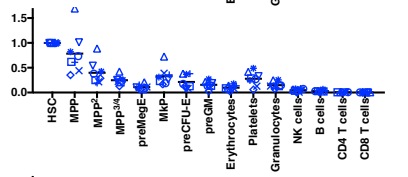

12 weeks
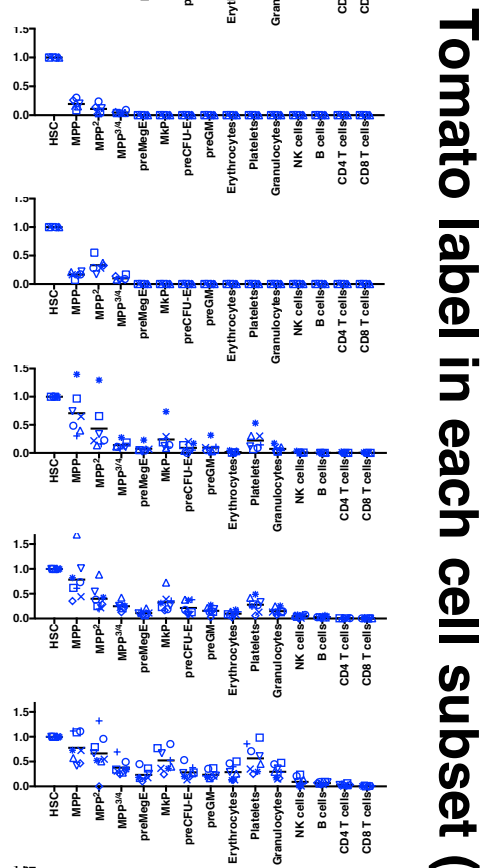

16 weeks

28 weeks
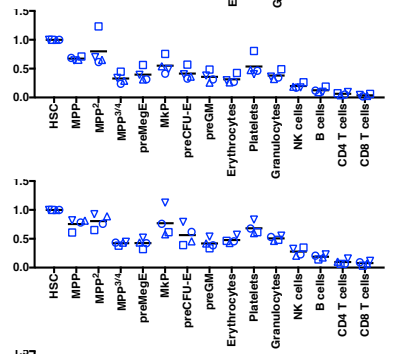

32 weeks

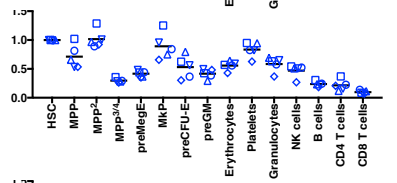

83 weeks

Fig. S2. Label induction and progression in 1x Tamoxifen treated adult Fgd5 ${ }^{\text {CreERT2/+ }}$ Rosa26 $^{\text {Tomato/+ }}$ mice. Left column: percentages of Tomato ${ }^{+}$cells among the indicated hematopoietic subsets in bone marrow and peripheral blood at the indicated time after a single Tamoxifen injection. Right column: ratio of the $\%$ of Tomato $^{+}$cells in the indicated hematopoietic cell subsets relative to the \% of Tomato $^{+} \mathrm{HSCs}$ in corresponding mice. Mice were analyzed 24h $(n=6)$, 48h $(n=6)$, 96h $(n=6), 4 w(n=7), 8 w(n=8), 12 w(n=8)$, $16 w(n=4), 28 w(n=4), 32 w(n=5)$ and $83 w(n=3)$ after Tamoxifen injection. Cohorts of mice were injected with Tamoxifen in five different experiments. Symbols indicate individual mice and bars indicate the mean Tomato level at each time point evaluated. 


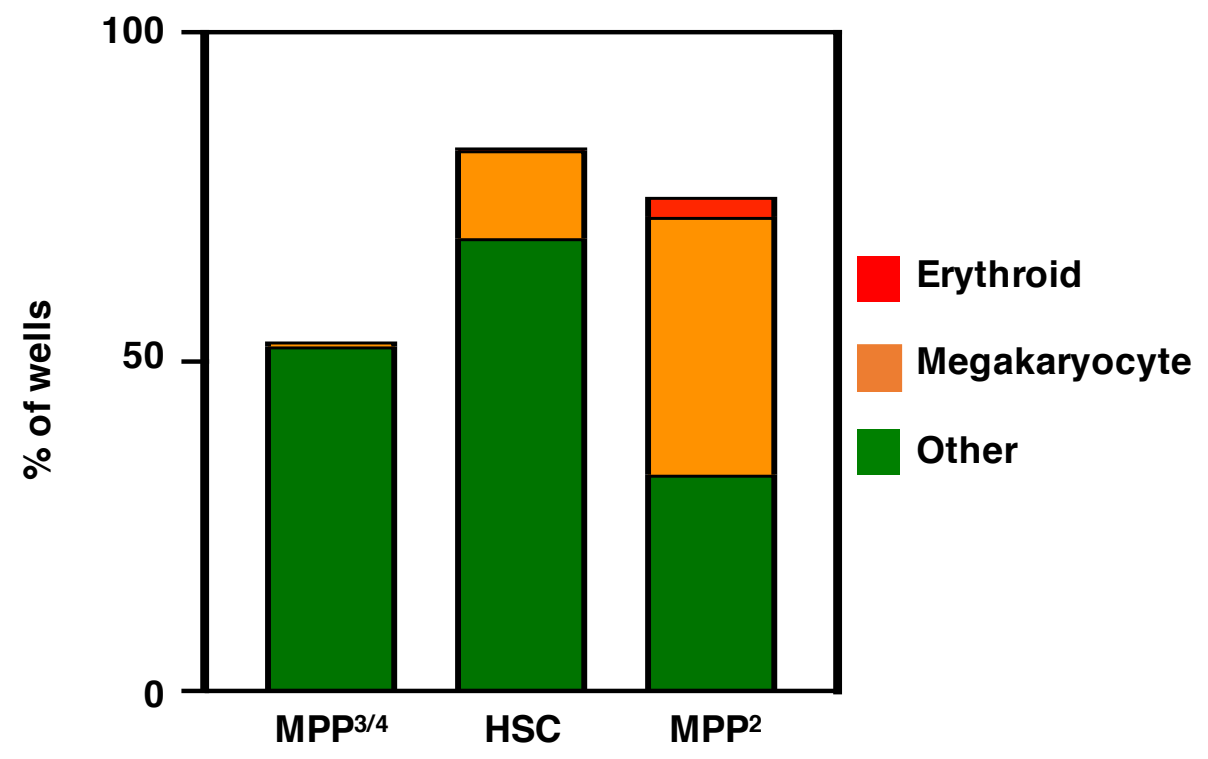

Fig. S3. In vitro differentiation potential LSK HSPCs. Single GMLPs $(\mathrm{n}=$ 279), HSCs $(n=240)$ and LSKCD $150^{+} C D 48^{+}$cells $(n=460)$ were seeded into Terasaki wells and cultured for 6 days before scoring wells for erythroid cells and megakaryocytes by microscopic evaluation. The $\%$ of wells containing erythroid cells (red), megakaryocytes (orange) or cells other than erythroid or megakaryocytes (green) are plotted in filled bars from the different indicated cells evaluated. 


\section{\% Tomato+ in each cell subset (Figure 4D)}

Juvenile mice

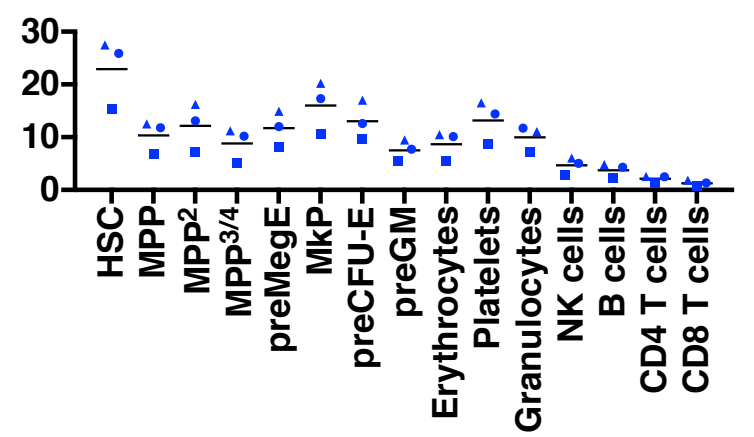

Aged mice

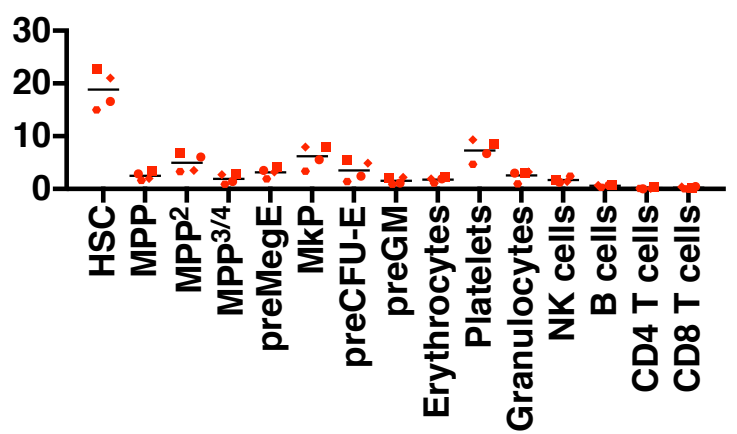

Fig. S4. Aging associates with reduced multilineage HSC contribution. The percentages of Tomato+ cells among the indicated hematopoietic cells in bone marrow and peripheral blood 18 weeks following injection of Tamoxifen. 
Table S1. Definitions of cells used throughout study.

\begin{tabular}{|c|c|c|}
\hline ORGAN & NOMENCLATURE & PHENOTYPE \\
\hline \multirow[t]{11}{*}{ Bone marrow } & $\begin{array}{l}\text { Myeloid } \\
\text { progenitors }\end{array}$ & Lin $^{-}$-kit ${ }^{+}$Sca1 ${ }^{-}$ \\
\hline & LSK & Lin $^{-}$c-kit ${ }^{+}$Sca $1^{+}$ \\
\hline & HSC & Lin c-kit $^{+}$Sca1 ${ }^{+}$CD $150^{+}$CD48- \\
\hline & MPP & Lin $^{-} \mathrm{c}-\mathrm{kit}^{+}$Sca1 ${ }^{+} \mathrm{CD} 150^{-} \mathrm{CD} 48^{-}$ \\
\hline & $\mathrm{MPP}^{2}$ & Lin $^{-} \mathrm{c}-\mathrm{kit}^{+}$Sca $1^{+} \mathrm{CD} 150^{+} \mathrm{CD} 48^{+}$ \\
\hline & $\mathrm{MPP}^{3 / 4}$ & 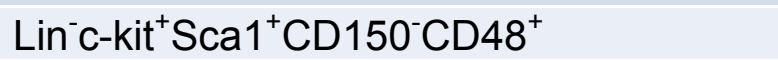 \\
\hline & MkP & Lin $^{-}$c-kit ${ }^{+}$Sca1-CD $150^{+}$CD $41^{+}$ \\
\hline & GMP & Lin $^{-}$-kit $^{+}$Sca1-CD150-CD41-CD16/32 ${ }^{+}$ \\
\hline & PreGM & $\begin{array}{l}\text { Lin }^{-} \mathrm{c}-\mathrm{kit}^{+} \mathrm{Sca} 1^{-} \mathrm{CD} 150^{-} \mathrm{CD} 16 / 32^{-} \mathrm{CD} 41^{-} \\
\text {CD105 }^{-}\end{array}$ \\
\hline & PreMegE & $\begin{array}{l}\text { Lin }^{-} \text {c-kit } \\
\text { CD105 }^{+}\end{array}$ \\
\hline & CFU-E & 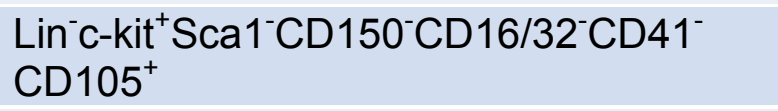 \\
\hline \multirow[t]{9}{*}{$\begin{array}{l}\text { Peripheral } \\
\text { blood }\end{array}$} & Erythrocytes/RBC & $\mathrm{FSC}^{\mathrm{mid}} \mathrm{SSC}^{\mathrm{mid}}\left(\operatorname{ter} 119^{+} \mathrm{CD} 45^{-} \mathrm{CD} 41^{-}\right)$ \\
\hline & Platelets & $\mathrm{FSC}^{\mathrm{low}} \mathrm{SSC}^{\mathrm{low}}\left(\mathrm{CD} 41^{+} \mathrm{CD} 150^{+}\right)$ \\
\hline & CD4+ T cells & $\mathrm{CD}^{+} \mathrm{CD}^{-}$ \\
\hline & CD8+ $\mathrm{T}$ cells & $\mathrm{CD}^{-} \mathrm{CD}^{+}$ \\
\hline & B cells & $\mathrm{CD}^{-} \mathrm{CD}^{-}{ }^{-} \mathrm{NK} 1.1^{-} \mathrm{CD} 19^{+}$ \\
\hline & NK cells & $\mathrm{CD}^{-} \mathrm{CD}^{-} \mathrm{NK} 1.1^{+} \mathrm{CD} 19^{-}$ \\
\hline & Monocytes & $\begin{array}{l}\mathrm{CD}^{-}{ }^{-C D} 8^{-} \mathrm{NK} 1.1^{-} \mathrm{CD} 19^{-} \\
\mathrm{SSC}^{\text {low }} \mathrm{CD} 11 \mathrm{~b}^{+} \mathrm{Gr} 1^{\text {neg/low }}\end{array}$ \\
\hline & Granulocytes & 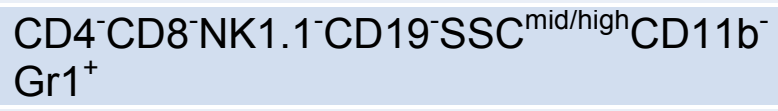 \\
\hline & Myeloid cells & $\mathrm{CD}^{-}{ }^{-} \mathrm{CD} 8^{-} \mathrm{NK} 1.1^{-} \mathrm{CD} 19^{-} \mathrm{CD} 11 \mathrm{~b}^{+}$ \\
\hline \multirow[t]{3}{*}{ Skin } & Langerhans cells & $\mathrm{CD} 1^{-} \mathrm{CD}^{-} 5^{+} \mathrm{Vg}^{-} \mathrm{TcRgd}^{-} \mathrm{F} 4 / 80^{+} \mathrm{Ly} 6 \mathrm{G}^{-}$ \\
\hline & Vg3d+ T cells & $\mathrm{CD} 1^{-} \mathrm{CD} 45^{+} \mathrm{Vg}^{+} \mathrm{TcRgd}^{+}$ \\
\hline & Granulocytes & 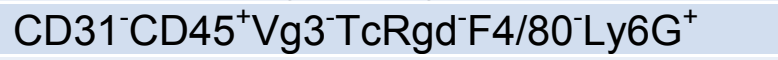 \\
\hline \multirow[t]{3}{*}{$\begin{array}{l}\text { Peritoneal } \\
\text { cavity }\end{array}$} & B1a & $\mathrm{CD} 19^{+} \mathrm{CD}^{+}$ \\
\hline & B1b & $\mathrm{CD}^{-} 9^{+} \mathrm{CD}^{-} \mathrm{CD} 11 \mathrm{~b}^{+}$ \\
\hline & B2 & $\mathrm{CD}^{1} 9^{+} \mathrm{CD}^{-} \mathrm{CD} 11 \mathrm{~b}^{-}$ \\
\hline
\end{tabular}


Table S2. List of analyzed genes in mutiplexed qRT-PCR gene expression analyses (Figure 2C).

\begin{tabular}{|l|l|}
\hline \multicolumn{2}{|c|}{ Gene list for gene expression analysis } \\
\hline Actb & Gata1 \\
\hline Alcam & Gata2 \\
\hline Ccnd3 & Gfi1b \\
\hline Cd34 & Hk3 \\
\hline CD41 & Hoxb3 \\
\hline Cd48 & Jun \\
\hline Cdkn1b & Ly6a \\
\hline Cdkn1c & Max \\
\hline Cdkn2c & Meis1 \\
\hline Cdkn2d & Mllt3 \\
\hline Cebpa & Mpl \\
\hline Cebpe & Ndn \\
\hline Csf1r & Nfat5 \\
\hline Csf2rb & Prdm16 \\
\hline Dnmt3a & Sdpr \\
\hline Dntt & Selp \\
\hline Egr1 & Sfpi \\
\hline Epor & Slamf1 \\
\hline Fgd5 & Tbp \\
\hline Flt3 & Tek \\
\hline Fos & Trib2 \\
\hline Gadd45a & Vwf \\
\hline Gadd45b & Zfp521 \\
\hline Gapdh & Zfpm1 \\
\hline & \\
\hline
\end{tabular}

